NBER WORKING PAPER SERIES

\title{
REGULATION OF HEALTH, SAFETY, AND ENVIRONMENTAL RISKS
}

\author{
W. Kip Viscusi \\ Working Paper 11934 \\ http://www.nber.org/papers/w11934
}

\author{
NATIONAL BUREAU OF ECONOMIC RESEARCH \\ 1050 Massachusetts Avenue \\ Cambridge, MA 02138 \\ January 2006
}

This research is supported by the Harvard Olin Center for Law, Economics and Business and by the Harvard Program on Empirical Legal Studies. Rob Stavins provided excellent detailed comments on a draft of this paper. The views expressed herein are those of the author(s) and do not necessarily reflect the views of the National Bureau of Economic Research.

(C2006 by W. Kip Viscusi. All rights reserved. Short sections of text, not to exceed two paragraphs, may be quoted without explicit permission provided that full credit, including (C) notice, is given to the source. 
Regulation of Health, Safety, and Environmental Risks

W. Kip Viscusi

NBER Working Paper No. 11934

January 2006

JEL No. K32, Q2, J28, J17

\begin{abstract}
$\underline{\text { ABSTRACT }}$
This paper provides a systematic review of the economic analysis of health, safety, and environmental regulations. Although the market failures that give rise to a rationale for intervention are well known, not all market failures imply that market risk levels are too great. Hazard warnings policies often can address informational failures. Some market failures may be exacerbated by government policies, particularly those embodying conservative risk assessment practices. Labor market estimates of the value of statistical life provide a useful reference point for the efficient risk tradeoffs for government regulation. Guided by restrictive legislative mandates, regulatory policies often strike a quite different balance with an inordinately high cost per life saved. The risk-risk analysis methodology enables analysts to assess the net safety implications of policy efforts. Inadequate regulatory enforcement and behavioral responses to regulation may limit their effectiveness, while rising societal wealth will continue to generate greater levels of health and safety.

W. Kip Viscusi

Harvard Law School

Hauser 302

Cambridge, MA 02138

and NBER

kip@law.harvard.edu
\end{abstract}




\section{The Rise of Risk Regulation}

Beginning in the 1970s, there was a major wave of health, safety, and environmental regulation. In the United States, the government established new regulatory agencies with broad regulatory responsibilities for risk and environmental policy. Some of these agencies addressed risks to people, such as mortality and morbidity risks, while others focused on dangers to natural resources, such as endangered species, which affect people indirectly. Among these new federal agencies were the Environmental Protection Agency (EPA), the Occupational Safety and Health Administration (OSHA), the National Highway Traffic Safety Administration (NHTSA), the Nuclear Regulatory Commission (NRC), and the Consumer Product Safety Commission (CPSC). In some cases, these agencies inherited functions that already existed but had been scattered among other regulatory agencies, such as the U.S. Department of Interior. In other instances, these agencies had entirely new legislative mandates that greatly expanded the scope and character of regulation.

The creation of these agencies did not take place because there was a sudden increase in societal risk levels. Indeed, individual mortality risks levels of almost all kinds had been declining throughout the twentieth century and had been continuing to decline. For example, there were declines in accident rates at home and occupational fatalities throughout the past century, long before there was any government regulation in place. ${ }^{1}$ One exception to this mortality risk trend was the automobile fatality rate, which had increased overall due to the greater usage of motor vehicles. The motor vehicle death rate per 100,000 population peaked in 1937 and has exhibited an uneven but downward trend thereafter. However, the fatality rate per mile driven had continued to decline quite steadily so that in 2003 it was 1.56 per 100,000 vehicle miles, as compared to 4.88 per 100,000 vehicle miles in 1970 and 14.68 per 100,000

\footnotetext{
${ }^{1}$ The statistics cited in this paragraph are drawn from the National Safety Council (2004).
} 
vehicle miles in 1937. Auto safety became the first target of the emerging consumer movement that had been fostered in part by the auto safety efforts of Ralph Nader (1965). Environmental risks displayed a somewhat different temporal trajectory, as many concentrations of air and water pollutants increased until the early 1970s and declined thereafter once the environmental regulations were instituted, as documented by Freeman (2002). These regulations in turn have led to steady improvements in environmental quality with only a few exceptions, such as carbon dioxide, which has continued to rise. Support for both consumer protection and risk regulation generally also can be traced to rising societal wealth levels that increased individual valuations of risk reduction, thus increasing the demand for regulatory intervention.

The role of the courts with respect to risk also increased since the 1970s. A noteworthy period was the mid-1980s when liability insurance premiums for general liability and medical malpractice approximately tripled in a two-year period, prompting claims that there was a "liability crisis." The counterargument to the crisis view was that the upsurge in premium rates reflected the normal ebb and flow in the insurance industry known as the underwriting cycle. Periodic declines in interest rates led to an associated increase in premium rates because the return insurers received on the invested premium amounts had declined. Although the increases in liability costs abated, the costs imposed by tort liability remained at or above the mid-1980s levels, in part because the scope of liability rules had expanded.

The expanded role of liability in some cases encouraged additional regulatory activity. A notable example is that of asbestos. Traditionally there had been comparatively lax regulation of asbestos, in that the risks were substantial and could be reduced at modest cost. The wave of asbestos-related lawsuits spurred the imposition of stringent occupational and environmental standards. After a period of inadequate regulation of asbestos, both EPA and OSHA imposed a 
succession of asbestos regulation standards that greatly altered the tradeoff between cost and risk and, in the view of some observers, such as Breyer (1993), erred on the side of being too stringent.

This pattern of liability spurring further regulation has continued in other contexts as well. Three principal examples of the interaction of regulation and litigation are breast implants, lead paint, and cigarettes. In the case of breast implants, these medical devices had been exempted from serious scrutiny from a safety standpoint until a series of successful lawsuits led the FDA to suspend the use of silicone breast implants until the safety issues could be resolved, as described in Hersch (2002). Lutter and Mader (2002) found that for lead paint the causality was in the other direction as 1978 CPSC regulations had banned the use of lead paint, but because the paint remains in older dwellings there have been a spate of lead paint-related lawsuits, including major class actions. For the past decade there has been a synergistic relationship between regulation and litigation of the cigarette industry, much of which was stimulated by the settlement of a series of state attorney general lawsuits against the industry for close to $\$ 250$ billion, as discussed in Viscusi (2002).

While the interactive effects of regulation and litigation have generated substantial controversy, there is a general consensus that there should be health, safety, and environmental regulation. The main debate is over the targets for regulatory action, the modes of intervention selected, and the stringency of the regulation. A substantial body of economic research has focused on striking the appropriate balance between risk reduction and cost and on ways in which regulations can be designed to maximize social welfare. ${ }^{2}$ While this formulation has widespread acceptance in the economics literature, economists' concern with maximizing social welfare often is inconsistent with more narrowly defined approaches taken by regulatory

\footnotetext{
${ }^{2}$ Among the more comprehensive treatments of this issue are Breyer (1993), Viscusi (1992), and Sunstein (2002).
} 
agencies, which may focus on less balanced objectives, such as the promotion of clean air irrespective of other concerns, such as cost.

The focus of this chapter is on the theoretical and empirical methodologies that have been developed to analyze the substantive economic issues in this area. In some instances, the economic frameworks can be used to provide guidance for policy design, while in other cases the emphasis is on assessments of policy performance for what continues to be the most costly area of government regulation. Ideally, if economic efficiency is our objective, these efforts should also produce commensurate benefits so that these policies will benefit society on balance. Moreover, policies should strive to produce the greatest spread between benefits and costs.

The chapter is organized as follows. In Section 2, I construct the basic individual choice model involving a risky decision. Even if choices are not ideal and there is a rationale for intervention, how people would choose to bear risks in an efficient context frequently serves as the reference point for guiding policy interventions. After I examine the sources of market failure in Section 3, Section 4 develops the analysis of informational types of regulatory interventions, which address the frequent shortcoming in risk contexts. Before considering the use of benefit-cost analysis in Section 7, this chapter first explores risk assessment procedures in Section 5 and risk valuation in Section 6. How the newly developed risk-risk analysis approach would alter these policy judgments is the subject of Section 8, while Section 9 examines enforcement of risk and environmental regulations.

\section{Model of Risky Decisions}

Before considering the role of government regulation and tort liability, it is useful to begin with a model of rational individual choice. The effect of inadequacies in such choices on market performance is a principal rationale for intervention. In addition, the thought experiment 
of how people would make decisions involving risk if markets functioned perfectly and choices were fully rational provides a useful reference point for establishing the appropriate tradeoffs between risk and cost. Thus, what balance would individuals themselves choose to strike between these two components of decisions?

For concreteness, let us focus on two decisions - a private decision to invest in good health as well as a market decision involving the individual's choice of a potentially hazardous job. Within the job choice context, workers will require additional wage premiums to face additional risk. The model could be developed in parallel fashion for product risks rather than job risks. The product risk counterpart is directly analogous. Just as workers will require higher wages to work on jobs posing greater risk, consumers will require a reduced price to lead them to buy more dangerous products. Since most empirical studies of money-risk tradeoffs have used labor market data on wages and risk to impute these tradeoffs, the risky job choice decision will be the case study examined below.

Note that in both the product market case and job market case, the parties are in a contractual relationship. A company with hazardous jobs posing risks that are known to workers will not attract individuals to the jobs unless the company pays a sufficient wage to match the workers' utility level in alternative employment. In contrast, many risky decisions, such as the decision to pollute, involve risks to third parties that are not part of a contractual relationship. These third party risks will be addressed further within the discussion of externalities.

Suppose that the individual can choose the level of job safety $s$ from a range of continuous market opportunities $w(s)$, where $w_{s}>0$ and $w_{s s} \leq 0$. The individual risk level is also dependent on the level of health-enhancing expenditures, $h$. For concreteness let there be two states of the world, good health and death, for which the pertinent utility functions are $u$ and $v$, 
where $v$ is a bequest function. Assume that people are risk-averse or risk-neutral and that being alive is preferable to the alternative: $u(x)>v(x)>0, u^{\prime}(x)>v^{\prime}(x)$, and $u^{\prime \prime}(x), v^{\prime \prime}(x) \leq 0$. The probability $\pi$ of being in the good health state $\pi(s, h)$ increases with the safety level $s$ and the health-related expenditures, $h$. The risk of death $1-\pi(s, h)$ is assumed to be perceived accurately. Finally, let $y$ be the individual assets.

An expected utility (EU) maximizer will consequently choose $\mathrm{s}$ and $\mathrm{h}$ to

$$
\operatorname{Max}_{s, h} \mathrm{E} U=\pi(s, h) u((y+w(s)-h))+(1-\pi(s, h)) v(y+w(s)-h) .
$$

The first-order condition for the optimal value of $h$ is

$$
\frac{1}{\pi_{h}}=\frac{u-v}{\pi u^{\prime}+(1-\pi) v^{\prime}}
$$

and it can be shown that the comparable requirement for $s$ is

$$
\frac{-w_{s}}{\pi_{s}}=\frac{u-v}{\pi u^{\prime}+(1-\pi) v^{\prime}}
$$

The term on the left side of equation 3 is the negative of the marginal change in wages in response to increases in the safety level $s$ divided by the marginal effect of the job safety level $s$ on the probability of survival. If the safety level metric $s$ is equivalent to the probability of survival, then $\pi_{s}=1$. For small changes in $s$, the value of $-w_{s}$ will then equal the marginal wage increase needed to face added risk and, equivalently, the negative of the marginal wage increase for greater levels of safety. This compensating differential term is set equal to the utility level difference between the two states, which is normalized by dividing by the expected marginal utility of consumption.

In the case of equation 2, the individual sets the marginal value of risks to life as revealed by health expenditures equal to the difference in utility level between the two states divided by the expected marginal utility of consumption. For the job safety choice reflected in equation 3 , 
the worker also sets the marginal value of risks to life equal to the difference between the utility levels in the two states divided by the expected marginal utility of consumption. Putting the two conditions above together, we have

$$
\frac{1}{\pi_{h}}=\frac{-w_{s}}{\pi_{s}}=\frac{u-v}{\pi u^{\prime}+(1-\pi) v^{\prime}}=\text { VSL }
$$

where VSL is the marginal value of statistical life, which is reflected throughout one's risktaking and risk-reducing decisions.

These results have several implications for policy. First, if people are cognizant of the risks, expected utility maximizers will choose the risk-reducing and risk-increasing activities so as to reflect a common VSL, which is a measure of their competing effects on individual welfare. The efficient level of risk is not zero in general. Second, this balancing will yield identical tradeoff rates across different domains of choice if there are smooth and continuous choices available. Whether the choice is a risky job, a risky product, a dangerous neighborhood, or beneficial health expenditures, if there is a continuum of choices people will set the tradeoff rates between risk and money to be the same in these different arenas. If particular areas of expenditure, such as allocations for regulations, are out of line with these tradeoff rates, it serves as a signal that economic efficiency could be enhanced.

Finally, as will be discussed below, equation 4 characterizes the value of statistical life as revealed through labor market decisions. Considerable empirical work has been devoted to estimating VSL levels in the labor market and in other contexts as well, where these values in turn will provide a yardstick for assessing the tradeoffs being made by regulatory policy. For example, if the tradeoff rate between risk and money is too low in a particular area compared to the tradeoffs the person is willing to make in other contexts, one might explore whether such 
highly cost-effective efforts can be expanded. These values in turn have served as the unit benefit values in assessing the benefits of government regulation.

The use of labor market VSL estimates in other policy contexts raises a variety of interesting theoretical concerns that have come under the general heading of the benefits transfer problem. First, the mix of people affected by a policy may have different attitudes toward incurring risk due to the heterogeneity of risk tradeoffs. Second, even for a particular utility function structure, the estimated VSL will decrease with the size of the baseline risk and with the extent of the risk reduction for which the willingness to pay value is being elicited. Third, labor market estimates reflect willingness to accept values, whereas policy evaluation hinges on willingness to pay values. For small changes in risk these values should be the same, but often are different in experimental studies, for which the willingness to accept values may be much larger.

The development here has been in terms of multiple risk-related activities that jointly affect the probability of survival $\pi$. The subsequent sections will frequently simplify the formulation of the probabilistic component by focusing on the decision context in which there is only a single risky activity rather than multiple choices that influence risk. With a more restricted model of that type, the person chooses the overall fatality risk directly within the context of a single choice situation, such as the riskiness of one's job. Adopting simplifications along these lines is often instructive, but at times it will also prove useful to recall the more general result that optimal risk taking will involve comparable risk-money tradeoffs across different domains of choice.

\section{Sources of Market Failure}


If markets functioned perfectly then there would be no need for government risk regulation. People would knowingly choose products, jobs, and activities to maximize their expected utility, and outcomes would be efficient. The various departures from the idealized economic world consist of a series of possible market failures to be reviewed briefly below. Increasingly, regulatory agencies are beginning to discuss these market failures in their efforts to justify intervention rather than simply assuming that new regulations are always desirable. Even if there is a shortcoming of markets, whether a regulation will in fact enhance societal welfare must be assessed as well. Thus, the existence of a market imperfection does not necessarily imply that a particular regulation will be beneficial.

\subsection{Imperfect Perception of Risk}

\subsection{A Biases in Risk Beliefs}

A potential shortcoming in individual choices involving risk can arise if people don't understand the risks involved so that there is a systematic bias in their risk beliefs. It is rare that people know the exact risks posed by their risky decisions. What is the reduced probability of death that results from purchasing a car with side curtain air bags or buying a house in a less polluted neighborhood? People may not have precise and accurate assessments of these or many other risks they face. However, a lack of such knowledge does not necessarily imply that there is a market failure that would give regulation or tort liability a role to play. We must first examine the nature and extent of the problem and how it affects decisions as compared to choices people would make with an accurate information reference point. Risk underestimation leads to too much risky activity, and risk overestimation leads to the opposite problem.

In many instances, it does not matter a great deal if risk perceptions are accurate or that if we make sound choices with respect to risk. The stakes are often small and involve few costs of 
error that cannot be corrected with better future decisions. Errors may be critically important with respect to catastrophic events, which tend to have small probabilities. Catastrophic risks to individuals and property are the main target of both regulatory policy and tort liability. ${ }^{3}$

For concreteness, consider the product market case in which there is a risk $p^{*}$ of injury from the product. In terms of the previous multi-risk model, $p^{*}$ corresponds to the value of 1 $\pi(s, h)$. Suppose the consumer has a subjective assessment of this risk given by $p$, with associated precision $\gamma$, where $\gamma$ is the equivalent number of draws from a Bernoulli urn that is reflected in the person's subjective beliefs. ${ }^{4}$ Higher values of $\gamma$ imply more precise probabilistic beliefs.

Rational expected utility maximizers engaged in some single period decision should treat subjective risk beliefs as equivalent to objective risk measures. Thus, if $p=p^{*}$, the subsequent choices will be expected utility maximizing, based on the true risk levels. If $p<p^{*}$, people underestimate the risk, while if $p>p^{*}$ people overestimate the risk. The fact that people have subjective risk beliefs and may not be fully informed consequently does not imply that people necessarily underestimate the risk and engage in too much risk taking behavior, since it is not necessarily the case that $p<p^{*}$.

How risk beliefs diverge from the actual risk levels is an empirical issue. For hidden risks, such as the presence of trace amounts of benzene in Perrier, it may be that people underestimated the risk before the presence of benzene was discovered, since this was a situation of ignorance. People simply did not know that there was benzene in Perrier, though the actual risks were never that great. In situations of ignorance, people will tend to respond inadequately to risks, as has been shown with respect to natural disasters by Kunreuther et al. (1978). Once

\footnotetext{
${ }^{3}$ A useful survey of issues pertaining to low probability-high consequence events is that by Camerer and Kunreuther (1989). A further discussion of catastrophic risks appears in Posner (2004).

${ }^{4}$ The discussion in this chapter assumes that probabilistic beliefs can be characterized by a beta distribution with the parameterization to be discussed in the text.
} 
the risks are publicized, as in the Perrier benzene case, it is likely that the public overestimated the risks. Indeed, even after eliminating the presence of benzene, the product never recovered its earlier share of the bottled water market. Thus, substantial media coverage may lead to risk overestimation rather than accurate risk beliefs.

In some extreme instances, the media coverage of negligible risks may lead regulators to undertake policy actions not warranted by actual risk levels. McClelland, Schulze, and Hurd (1990) found that the public has a very inaccurate perception of the risks posed by hazardous waste sites but that these erroneous beliefs adversely affect housing prices. These and similar results raise the policy question of the extent to which policies should address risks that are perceived and not real, but nevertheless may have significant economic consequences in that markets may react to perceptions rather than actual risks.

While discussions of the role of tort liability and risk regulation often hypothesize that people underestimate risks, that pattern does not necessarily hold. Errors in risk beliefs do not necessarily imply that people always underestimate risks. Biases in risk beliefs are not random but vary in a variety of systematic ways. An important risk dimension that has received extensive empirical study is the magnitude of the risk. In the case of mortality risks, for example, the general pattern is that people overestimate small risks and underestimate large risks. ${ }^{5}$ Thus, people tend to overestimate small risks such as those from botulism and lightning strikes, and they underestimate more consequential risks such as the risk of heart disease. To the extent that job risks and product risks are small, people may on balance overestimate these risks more often than underestimating them, provided of course that the risks are not hidden and there is some awareness that a risk is present. Assessments of whether there is a market failure

\footnotetext{
${ }^{5}$ See the early study by Lichtenstein et al. (1978) of this relationship. Fischhoff et al. (1981) examine these and many other salient biases in risk beliefs.
} 
stemming from risk underestimation consequently depends on the level of the risk and the associated level of risk perceptions in the particular market context.

The tendency to overestimate small risks has an interesting corollary as well. If people exaggerate the importance of small risks, then they will overvalue policies that reduce the risk to zero. The reason is that they will perceive a greater reduction in the risk than is actually being generated. Thus, people will be willing to pay a zero risk premium. People will be willing to pay more for a reduction of a risk to zero than they would for a comparable actual risk reduction that does not reduce the risk to zero.

Reducing the risk to zero may offer additional benefits to the risky decision maker. Once the risk is completely eliminated, there is no reason to worry about the risk or factor the presence of a risk into one's decision making. Unless the anxiety reduction benefits of reducing a risk to zero are substantial, it is generally believed that the premium people place on zero risk levels represents a form of irrationality. The importance of this phenomenon has not been lost on government regulators. We are usually assured that our food is "safe" rather than being told that there is a low but nonzero probability that the food will make us ill.

A substantial literature has examined a wide variety of other forms of systematic biases in risk beliefs. For example, people tend to overreact to increases in the risk level from its accustomed risk. Researchers have referred to this phenomenon as reference risk bias and status quo bias. ${ }^{6}$ Thus, changes in a product that increase the risk will tend to produce an exaggerated response, implying a higher rate of tradeoff than comparable decreases in risk.

Consequently, people may be willing to pay modest amounts for significant reductions in the risk posed by a product. However, if the risk of the product were to increase by a small

\footnotetext{
${ }^{6}$ For discussion of these effects, see Viscusi, Magat, and Huber (1987) and Samuelson and Zeckhauser (1988) respectively.
} 
amount, they often refuse to purchase the product altogether and, if they are willing to purchase it at all, they require a much more substantial price reduction than the amount they were willing to pay for the risk decrease. ${ }^{7}$

Substantial publicity regarding a risk may lead to risk overestimation as well. ${ }^{8}$ This result runs counter to the usual economic assumption that additional information leads to more informed judgments. The reason is that the information often takes the form of publicizing only the number of adverse risk events rather than the risk frequency. We often hear reports of the number of ATV deaths or Mad Cow disease victims, but these statistics are seldom put in the context of the total number of ATVs in use or the size of the beef-eating population that is at risk. What is being publicized is the numerator of the risk calculation, rather than the numerator and the denominator or the overall risk frequency. ${ }^{9}$

The extent of the publicity devoted to the number of deaths in the numerator of a risk calculation than the exposed population that comprises the denominator of the risk calculation also may differ depending on the risk context.. A dramatic risk event, such as the 9/11 terrorist attack on the World Trade Center, garnered much more media coverage than routine auto accidents even though more people are killed every month in the U. S. on highways than in this worst case terrorist attack. Tornadoes, earthquakes, and hurricanes also generate dramatic media coverage and likely risk overestimation. The role of responses to media coverage makes the extent of publicity given to the hazard a pertinent factor in assessing the direction of bias in risk beliefs.

\footnotetext{
${ }^{7}$ Viscusi, Magat, and Huber (1987) provide supporting empirical evidence for two representative consumer products.

${ }^{8}$ Fischhoff et al. (1981) discuss the role of publicity with respect to risk beliefs.

${ }^{9}$ Viscusi and Zeckhauser (2004) term this phenomenon "the denominator blindness effect," and they document the effect in several contexts.
} 
The substantial publicity given to smoking risks has led to overestimation of these risks compared to scientists' estimates of the actual level of the hazard. For example, U.S. government estimates of the lung cancer risks of smoking over a smoker's lifetime range from 0.06 to 0.13 , whereas the lung cancer risk perceptions by the general public range from 0.43 to 0.48 for national surveys undertaken from 1985 to $1998 .{ }^{10}$ Similar results have been found for Spain and Taiwan even though the warnings environment in those countries is different. ${ }^{11}$

\subsection{B Risk Ambiguity}

Not all risks are known with precision. Thus, it is not simply the level of these risk beliefs that may be consequential, but also their precision. Examination of the role of the tightness of risk beliefs comes under the general heading of risk ambiguity.

A potential bias in people's treatment of risk that has played a prominent role in the literature stems from the influence of risk ambiguity. The classic Ellsberg (1961) Paradox focuses on people's attitude with respect to ambiguous risks, that is, risks for which the subjective probability judgment with respect to the probability $p$ represents a situation of imperfect information. ${ }^{12}$ Lower values of $\gamma$ reflect less precise probabilistic beliefs. In situations in which individuals have an opportunity to win a prize, the standard Ellsberg Paradox result is that people would prefer precise probabilities of success to imprecise probabilities, for any given mean value of the probability. Analogous results also hold with respect to the chance of a loss as people exhibit ambiguity aversion with respect to imprecise probabilities of adverse effects. Thus, in situations in which risks are ambiguous, such as the imprecisely understood risks of

\footnotetext{
${ }^{10}$ Viscusi (2002) presents the series of studies on U.S. smoking behavior.

${ }^{11}$ Estimates for Taiwan are reported by Liu and Hsieh (1995), and findings for Spain are discussed in Viscusi (2002).

${ }^{12}$ Raiffa (1961) provides interesting lottery counterexamples to the Ellsberg Paradox to demonstrate the irrationality of succumbing to the Ellsberg Paradox. The literature on risk ambiguity is quite extensive. See Camerer and Weber (1992) for a survey and Kunreuther, Hogarth, and Meszaros (1993) for an analysis of insurance market effects.
} 
mad cow disease, one would expect people to exhibit ambiguity aversion and be reluctant to incur these imprecisely understood hazards, as compared to precisely understood risks of the same magnitude. The unwillingness to incur ambiguous risks will consequently deter people from making efficient market choices. They incur too small a risk in situations in which the risks are identified but are not well understood.

Because citizen preferences influence pressures for government policies, irrational responses to ambiguous risks have led to similar biases in the formulation of government policy. An interesting case study of the role of ambiguity aversion is government regulation of synthetic risks as opposed to natural carcinogens. Many seemingly safe foods pose some minor carcinogenic risk, including mustard and coffee, and many of these natural carcinogens pose greater risks than some synthetic chemicals that are regulated. ${ }^{13}$ Particularly for regulations by the Food and Drug Administration, the magnitude of the cancer risk is not especially influential in determining whether a particular chemical is regulated. What does play a dominant role is whether the chemical is a synthetic. ${ }^{14}$ Focusing on this particular character of the risk rather than the magnitude of the hazard is a reflection of how risk ambiguity aversion has moved from the realm of being an irrationality that has been of academic interest to a property of government policy making.

How the lack of full information plays out in a particular market context depends on the character of the risk. Most hazards involve low probability events and risks that are not fully understood. Each of these attributes will lead people to be more reluctant to incur risks than they

\footnotetext{
${ }^{13}$ For evidence on carcinogenicity of different chemicals and foods, see Ames and Gold (1990) and Ames, Profet, and Gold (1990).

${ }^{14}$ Econometric evidence documenting this bias for the carcinogen potency data base set of chemicals is presented in Viscusi (1998). For a sample of 267 synthetic chemicals, 50 percent were not carcinogenic, which is similar to the 52 percent figure for the 98 natural chemicals studied. However, 47 percent of these synthetic chemicals were regulated by the FDA, compared to 34 percent for the natural chemicals, even thought the carcinogenicity of the synthetic chemicals was lower.
} 
would be if fully informed of the risk. The opposite problem arises for some very large risks and risks that are truly hidden, such as undisclosed prescription drug interactions. The early and extensive regulation of information disclosures for drugs is reflective of the importance of such disclosures when the risks are hidden.

\section{$\underline{3.2 \text { Irrational Behavior and Addiction }}$}

While most analyses of departures from efficient market conditions pertaining to risk decisions involve inadequate risk information, there are other possible shortcomings of choices as well. The most prominent of these failures pertains to addiction. From an economic standpoint, addiction generally pertains to market situations in which consumption of a good now leads one to prefer greater levels of consumption of that good in the future. Altering that consumption pattern also imposes substantial costs, making it difficult for the individual to change such consumption behavior. Smoking, drinking, illegal drug use, and overeating have played the greatest roles as case studies in the addiction literature.

Whether there is a market failure with respect to addiction depends on the nature of the choice process. Under the rational addiction models, such as those espoused by Becker and Murphy (1988) and by Becker, Grossman, and Murphy (1996), individuals anticipate their future addiction and rationally choose to become addicted. In their model, fully anticipated addictions do not necessarily involve a market failure. Rather, people could rationally choose to become addicted to a product even though giving up the addiction may be costly and the product itself may be quite dangerous.

The basic rational model of addiction developed by Becker and Murphy (1998) and Becker, Grossman, and Murphy (1994) recognizes that current consumption of the addictive commodity $c_{t}$ depends on past consumption of that good $c_{t-1}$ in the previous period. Models 
postulating irrational behavior likewise make that assumption about the intertemporal dependence of consumption. A distinctive feature of rational addiction models is that when people choose to become addicted, they anticipate that current consumption will increase their desired future consumption levels $c_{t+1}$.

Within an infinite time horizon framework, the rationally addicted consumer will choose consumption of the addictive product to

$$
\operatorname{Max} \sum_{t=1}^{\infty} \beta^{t-1} u\left(c_{t}, c_{t-1}, y_{t}, e_{t}\right)
$$

where $r$ is the rate of interest, $\beta$ is the discount factor $1 /(1+r), y_{t}$ is income in year $t, e_{t}$ is unmeasured life cycle variables, and the utility maximization is subject to a lifetime budget constraint. After assuming that the utility function is quadratic in $y_{t}, c_{t}$, and $e_{t}$, Becker, Grossman, and Murphy (1994) show that the lifetime consumption trajectory for an addictive good, such as cigarettes, satisfies

$$
c_{t}=\theta c_{t-1}+\beta \theta c_{t+1}+\theta_{1} p_{t}+\theta_{2} e_{t}+\theta_{3} e_{t+1}
$$

where $p_{t}$ is the price of cigarettes in year $t$, and the $\theta$ terms are parameters that depend on the individual's utility function and discount rate. As in standard models of consumer behavior, increasing the current price $p_{t}$ does have a negative effect on consumption. For addictive goods, past consumption leads to higher desired levels of current consumption. ${ }^{15}$ The greater the effect of past consumption on current consumption, as reflected in higher values of $\theta$, the more addictive the commodity is. Similarly, if addiction is rational and anticipated, future price levels that are anticipated should have a greater effect on consumption than unanticipated future price shocks. For analogous reasons, long-run price effects will have a greater effect on consumption than is reflected in the short-run price effect.

\footnotetext{
${ }^{15}$ This condition also requires that $p_{t}, e_{t}, e_{t+1}$, and the marginal utility of wealth are held constant.
} 
A quite different perspective offered by Schelling (1984) is that individuals who are addicted are engaged in a continuing battle for self-control. If people behave myopically and do not place a sufficiently great weight on their future selves, then according to this view people will tend to engage in too much behavior that is addictive, leading to a rationale for either direct regulation or taxation of the addictive product.

A similar market failure has been hypothesized by Gruber and Koszegi (2001). In their model, people suffer from time inconsistency in their choices. For example, people may exhibit hyperbolic discounting in which the rate of time preference for immediate rewards is much greater than for deferred payoffs. Moreover, their formulation shares some empirical predictions with the rational addiction framework, making it difficult to disentangle whether the rational addiction model or the time inconsistency model is operative. In particular, the Becker, Grossman, and Murphy (1994) empirical result regarding the role of anticipatory behavior does not rule out the possibility of time inconsistency.

More recently, Bernheim and Rangel (2004) have drawn on the literature from neuroscience and cognitive psychology to develop a model of addictive behavior in which people initially engage in addictive behavior as a result of a mistaken consumption decision. The addicted consumers nevertheless continue with their addictive behavior as environmental cues trigger their subsequent consumption decisions.

The rationale for regulating addictive products often depends on the overall social implications of addiction. Potential harm to the addicted individual is of course an important component. However, addictions may impose other costs as well. Drunk drivers may kill pedestrians and other motorists, and heroin addicts may resort to crime to support their habit. Thus, externalities are often intertwined with most regulatory analyses of addictive behaviors. 


\section{$\underline{3.3 \text { Externalities }}$}

The classic rationale for government regulation in the risk and environmental area is the presence of externalities. While environmental pollution is the most common textbook example of an externality, externalities are present elsewhere as well. In workplace contexts, risky behavior on the part of some workers may lead to co-worker injuries, which has prompted government regulation of work practices and workplace conditions. Consumption choices by individuals may affect others adversely as well.

A company generating an externality on a third party will choose the level of activity to maximize its profits, which can also be recast as maximizing the difference between its benefits minus costs. The optimizing polluter will set marginal benefits equal to marginal costs, as in usual optimization frameworks. If the externalities are imposed on third parties, such as the general public, and there is no liability and no regulatory sanctions, then the marginal costs to the company will understate the social marginal costs, and the polluter companies will engage in two much of the risky activity. The existence of liability or regulatory sanctions for such harms will induce greater levels of care by imposing higher marginal costs on the firm. Using this formulation, Cohen (1986) illustrates the role of marginal benefits and marginal costs using oil spills as a case study. Based on reasonable empirical assumptions, he concludes that the Coast Guard's oil spill enforcement efforts appear to generate benefits in excess of costs. Whether the enforcement efforts are in fact socially optimal in terms of maximizing the spread between benefits and costs is less clear.

A notable recent example that has attracted considerable policy attention is with respect to sport utility vehicles, SUVs. ${ }^{16}$ These vehicles create two kinds of externalities for other cars. First, because SUVs have greater mass than the average car, they pose a greater threat to other

\footnotetext{
${ }^{16}$ See Gayer (2004) for an analysis of the accident costs associated with SUVs.
} 
vehicles because the risks posed in a crash involving two vehicles increase with respect to the ratio of the relative weight of the two vehicles. This risk factor is not a distinctive aspect of SUVs, as it is also shared by heavy cars. Second, the structure of SUVs also may be influential as well. Because many SUVs are based on frames adapted from small trucks, some SUVs have stiffer frames than cars and also often have bumper heights that do not align with the height of bumpers of cars, thus generating more damage to the other vehicle than if a car with the same weight had been involved in the crash.

Though there has yet to be any formal regulation of SUV designs, the policy discussions reflect the diversity of potential policy responses. First, to the extent that SUVs generate higher accident costs of a financial nature, this difference will already be reflected to a large extent in insurance rates and will be internalized by SUV owners. Second, there has been litigation in the courts claiming that SUVs do not strike a reasonable balance between risk and other product attributes, thus imposing inordinate risks to passengers in cars. If successful, these lawsuits could establish financial incentives for changes in SUV design. Whether such incentives are desirable, however, is not clear. It presumably would depend on whether there have been inadequacies in consideration of these issues in regulatory contexts by the NHTSA. Third, there may be government regulation of SUV design to address the safety issue. To the extent that vehicle weight is a concern, that risk factor is also present for very large cars. Similarly, the bumper height and stiff frame risk factors are present not just for SUVs but also for light trucks, as they served as the design on which many SUVs are based. If there is a judgment that there is a significant market failure, an efficient policy solution will require a comprehensive analysis of alternative product designs for a broad range of vehicles to strike some balance between these competing effects. 
There also may be consumption externalities of a positive nature. It has often been observed that with respect to the use of protective equipment, such as hockey helmets, that individuals are reluctant to use such equipment on their own because doing so would be a sign of weakness in this contact sport. However, if a critical mass of players can be required to wear helmets, then individuals will voluntarily choose to adopt these helmets. This situation reflects an n-person Prisoner's Dilemma of the type modeled by Schelling (1978). The observed market equilibrium from individual choices may lead to a less preferred outcome that leads to a lower payoff to all individuals than would a regulated outcome in which people were constrained to undertake behavior that conveyed positive externalities. An example of a policy remedy that will improve social welfare in such situations has been to require the use of hockey helmets and other protective devices for professional athletes.

In some cases, products may generate both positive and negative externalities. A noteworthy example pertains to the external financial costs of cigarettes. Smokers experience morbidity effects and have premature mortality compared to nonsmokers. As a result, there are externalities that increase some social costs, such as medical costs, fires, sick leave, and retirement benefit taxes that are not paid once smokers are dead. Other cost components, notably pensions, social security, and nursing home expenditures, are lower for smokers. On balance, excluding the role of excise taxes, cigarettes convey a net cost savings based on discount rates such as 3 percent or less and impose a net cost increase when the effects are evaluated at interest rates of 5 percent or more. Thus, there are both positive and negative externalities that have different trajectories over time, making the intertemporal weights much more consequential than in simpler externality situations such as with respect to air pollution emissions, which always 
impose a net external cost. ${ }^{17}$ One caveat regarding the self financing aspect of cigarette externalities is that the distribution of the benefits and costs varies depending on the particular externality, so that while on net there may be no net adverse financial externality, the parties responsible for the individual components may not all benefit. For example, even though smoking generates a 32 cent per pack saving in insurance and tax externalities, the present value of the rise in medical insurance costs due to smoking is 58 cents a pack evaluated at a 3 percent interest rate.

One also should be cautious in generalizing from the smoking results to other products. Alcohol use may appear to have similar properties in that excessive alcohol consumption is a risky consumer product. However, as shown by Manning et al. (1989), the substantial costs imposed by drunk drivers are a dominant concern that makes the negative externalities associated with this product loom particularly large.

\subsection{Modes of Intervention}

The existence of market failure need not imply that all possible interventions will be successful in improving market outcomes. The inefficiency that is present may be small, or it also could be the case that no intervention would be beneficial. However, if there is a desire for intervention, there are typically a variety of different forms that this intervention could take. Many of these issues pertain to the choice between regulation and litigation, which has been examined by Shavell (1987). ${ }^{18}$ However, even within a particular institutional structure, such as regulation, there may be different types of actions the regulator might adopt..

Consider a consumer's decision to purchase a dangerous product for which the actual risk is $p^{*}$ and the perceived risk is $p$, where $p<p^{*}$. Let the cost of the product be $c$ and the

\footnotetext{
${ }^{17}$ These results are reflective of the findings in both Manning et al. (1989) and Viscusi (2002).

${ }^{18}$ For a comprehensive assessment of the role of the liability system in a wide variety of contexts, see Shavell (2004).
} 
consumer's income be $y$. The consumer receives utility from consuming the product of $u(y-c)$ if the product doesn't cause injury, and $v(y-c)$ if the product does cause injury. Alternatively, the consumer could choose not to buy the risky product and reap utility $x(y)$. Suppose too that there is a social cost $g$ generated by adverse outcomes associated with the product's use. Thus, $g$ occurs with a probability $p^{*}$.

The consumer will purchase the risky product if

$$
(1-p) u(y-c)+p v(y-c)>x(y) .
$$

This purchase will be socially desirable if

$$
\left(1-p^{*}\right) u(y-c)+p^{*} v(y-c)-p g>x(y) .
$$

For this consumer choice problem there are consequently two potential sources of market failure creating a disparity between private decisions and social valuations.

To remedy the disparity between $p$ and $p^{*}$, the government could simply supply information. If the market failure is with respect to imperfect information, then information disclosure is a natural remedy, as will be discussed below in section 4. The impetus for this informational intervention could come voluntarily through market forces, but if these are inadequate, then either government regulation can require the information disclosure, as with nutrition labeling requirements, or there might be tort liability for firms that fail to disclose the pertinent risk information, as in failure to warn cases.

A second form of intervention that can be useful in aligning private and social incentives consists of tax or penalty schemes. Thus, a penalty value of $h$ can align private and social values for the consumer decision by setting

$$
(1-p) u(y-c-h)+p v(y-c-h)=(1-p *) u(y-c)+p^{*} v(y-c)-p * g .
$$

Whereas providing accurate information can align $p$ and $p^{*}$ but not address the externality $g$, the 
penalty $h$ can discourage consumer purchases in much the same way as would greater risk beliefs as well as imposing penalties, so that the external costs are incorporated in the consumer's decision. Thus, for our consumer choice problem, the regulation could be structured to provide the risk levels that people would choose if they were fully informed of the product risks and took full account of external costs they imposed with their choices. The various kinds of "sin" taxes, such as excise taxes on gasoline, alcohol, and cigarettes, are perhaps the most prominent of these types of financial incentive devices.

A third general mode of intervention is the use of government regulation. The form of such regulations can be quite diverse, as they might be technology-forcing regulations as in requirements with respect to the design of buses imposed by the U.S. Department of Transportation, or they might be performance-oriented requirements, as is the case with respect to permissible exposure limits for airborne carcinogens in the workplace or permissible levels of grain dust in grain elevators. Government regulation also may involve the use of monetary incentives and market-based systems, as discussed in the chapter by Revesz and Stavins.

The tort liability system also plays an instrumental role in many instances. As with most forms of government regulation, the financial penalties generated by tort liability are only triggered once the product risk falls below some critical level that ideally reflects some appropriate balancing of cost and risk. Liability costs often are substantial and will provide the same kinds of incentives for safety as would the financial incentives generated by regulation. For example, workplace fatality risks are reduced by about one-third due to the financial incentives provided by the U.S. workers' compensation system. ${ }^{19}$ Similarly, product liability costs affect incentives as well, as evidenced in the increased cost of vaccines in response to tort

\footnotetext{
${ }^{19}$ See Moore and Viscusi (1990) for an analysis of wage offsets from workers' compensation.
} 
liability for these products. ${ }^{20}$ These financial incentives in turn affect incentives for innovation, as small and moderate levels of liability costs increase firms' levels of research and development, product innovation, and patents for new products, which is in line with the conventional economic theory of deterrence. ${ }^{21}$ At extremely high levels of liability, however, these incentives may become counterproductive. Thus, firms may simply leave the market or stop producing a particular product if liability costs become excessive. ${ }^{22}$ The National Academy of Sciences (1990) attributed the exiting of firms from research on contraceptive devices to the chilling effect of tort liability.

A potential deficiency of ex post remedies such as tort liability is that the injuring party may be judgment-proof, especially for very large losses. For individuals, the result has been that states require mandatory automobile insurance so that parties who are victims of auto accidents can potentially recover damages from an injurer who otherwise would be insolvent. For corporations and other institutional entities, the judgment proof problem arises for catastrophic risks, making it desirable, for example, to have mandatory insurance. Whether safety incentives are created by insurance will depend on the extent of experience rating.

Liability has an additional disadvantage in terms of its ability to replicate the outcomes that would occur with perfect markets. Tort compensation for personal injuries generally provides for economic damages and coverage for noneconomic loss that is below the levels of the value of statistical life pertinent for establishing efficient incentives for accident prevention. Ex ante regulatory interventions can generate such incentives without the problem of providing excessive levels of insurance.

\section{Hazard Warnings and Risk Communication Policies}

${ }^{20}$ See Manning (1994) for an assessment of the higher prices resulting from vaccine litigation.

${ }^{21}$ See Viscusi and Moore (1993), who analyze the effect of liability costs on patents and new product introductions.

${ }^{22}$ See Huber (1988). 


\section{$\underline{4.1 \text { Principles for Hazard Warnings }}$}

The principal alternative to direct government regulation is the use of informational policies. Whereas government regulation often imposes restrictive limits on individual behavior, hazard warnings work through market processes and seek to address the informational inadequacy directly. Thus, people will then be able to choose the risky products or jobs that are consistent with their own preferences.

A separate rationale for hazard warnings policies is that often it is difficult to have command and control regulations for decentralized behavior. For example, consumers' use of dangerous pesticides is generally not monitored by the government but is undertaken without any direct supervision of the pesticide usage. In such contexts, hazard warnings serve to provide the information that people need in order to take appropriate precautions with respect to usage of the product. If the risk of misuse is especially great, then for these especially dangerous pesticide products the government frequently requires that the user be a certified pesticide applicator. Thus, rather than simply relying on warnings, the government requires additional training programs, but these programs are also informational in character. However, they are more intensive than on-product warning labels.

From the standpoint of efficient market operation, hazard warnings should provide new information in a convincing manner. The objective of warnings is to enable people to have accurate risk beliefs rather than to simply deter behavior. In that regard, information that simply reminds consumers of what they already know generally does not alter behavior and does not serve a constructive function. A prime example of such a reminder warning was the Buckle Up 
for Safety seatbelt campaign, which had a very disappointing effect on seatbelt use and traffic safety. $^{23}$

To see how these principles stem from an optimal Bayesian learning model, consider the following formulation. In the following example, risk information can be constructive. For simplicity the formulation will be in terms of a single choice that poses the risk of an accident. Suppose as before that individuals have prior risk beliefs $\mathrm{p}$ of some adverse outcome, with associated precision $\gamma$, where $p<p^{*}$, which is the true level of the risk. Suppose that the hazard warning conveys risk level $q$ with informational content $\xi$. Then after people have received the warning they will have posterior risk beliefs $p^{\prime}$ given by

$$
p^{\prime}=\frac{\not p+\xi q}{\gamma+\xi}
$$

assuming rational Bayesian updating. If warnings are not credible and have little information content, or a low value of $\xi$, then they will not alter risk beliefs and will play no constructive role. For very informative warnings, with high values of $\xi$ relative to $\gamma$, a value of $q$ equal to $p^{*}$ will lead people to have accurate risk beliefs. Reminder warnings, such as those with $p$ equal to $q$, will not alter mean risk beliefs. They will not discourage risk-taking behavior since their only effect is to increase the informational content to $\gamma$ to $\xi$, thus leading people to hold these risk beliefs more tightly. To the extent that ambiguity aversion leads people to avoid risk taking when risks are ambiguous, this greater precision will lead people to incur more risks rather than fewer risks if mean risk beliefs are unaffected.

In view of the proliferation of hazard warnings, it is worth noting too the potential shortcomings of excessive hazard warning information. The guiding principle for all

\footnotetext{
${ }^{23}$ For an evaluation of this effort, see Adler and Pittle (1984). These authors document other failures of informational programs as well.
} 
informational interventions is that they are subject to individuals' cognitive limitations. People have limited information processing capabilities. As Bettman, Payne, and Staelin (1987) observe, limitations on people's working memory make it important for warnings to be clear, well organized, and readily processed.

Conceptualization of these types of concerns have led to empirical studies of how these limitations affect the practice of effective warnings design. First, researchers have identified that there may be significant problems of information overload. ${ }^{24}$ If people are inundated with too much information, then the public may not be able to distinguish the most important risk messages that they receive. If, for example, everything in the supermarket is labeled dangerous, then it will not be feasible for consumers to make relative risk judgments. The second problem is that of label clutter. Although economists frequently claim that more information is desirable than less information, this principle does not necessarily extend to the practical world of warnings. More information may make it difficult for people with limited information processing capabilities to acquire the information and form reasonable probabilistic judgments.

\section{$\underline{4.2 \text { Responses to Multiple Information Sources }}$}

Often people are confronted not with a single information source but multiple information sources regarding a particular risk. In such situations involving a risk debate, how might people form their risk judgments? Using the same notation as before, let $q_{i}$ be the risk implied by information source $i$ and $\xi_{i}$ be the associated informational content of information source $i, i=1,2$. The credibility of each source and the risk level implied by their warning will vary with the type of risk, the identity of the source, and the basis for the risk judgment that is

\footnotetext{
${ }^{24}$ Many of these issues are discussed in Viscusi and Magat (1987) and tested in Magat and Viscusi (1992).
} 
presented. Then in this instance, posterior risk beliefs will be given by

$$
p^{\prime}=\frac{\not p+\xi_{1} q_{1}+\xi_{2} q_{2}}{\gamma+\xi_{1}+\xi_{2}} .
$$

The effect of risk debates on the public's risk beliefs may be complex, and will depend on how people interpret $q_{i}$ and $\xi_{i}$ in the context of a risk debate. Two effects have been established empirically. First, the existence of a risk debate may create a situation of risk ambiguity. Substantial expert disagreement regarding the risk can lead people to assess the risk as being greater than the midpoint value of the two risk experts, assuming that they have equal credibility. Thus, people believe that the ambiguous risk implied by these experts is equivalent to some precisely understood risk level s that is greater than the weighted average of the two risk experts' views. Second, situations in which there is a risk debate involving different entities are especially likely to generate a situation in which the equivalent precisely understood risk is much greater than the weighted average of the risk expert assessments, where these weights are $\xi_{1}$ and $\xi_{2}{ }^{25}$ This result holds even if the divergent risk experts' identities are reversed. Thus, if the government assesses the risk as being high and the polluting industry claims the risk is low, people tend to believe the high-end estimate. Similarly, if the industry expert assesses a high risk level and the government assesses a low risk level, people likewise assess the risk as being closer to the high-end estimate.

\section{$\underline{4.3 \text { A Brief History of Warnings }}$}

Although we now take hazard warnings policies for granted, in terms of the overall history of risk regulation hazard warnings are a relatively new development. Until early in the twentieth century, there was no legislation whatsoever pertaining to hazard warnings and also no regulatory requirements imposed by regulations. The first such legal requirement pertaining to

\footnotetext{
${ }^{25}$ These influences are examined in Viscusi $(1997,1998)$.
} 
warnings was the enactment by Congress of the Federal Caustic Poison Act in 1927. For the first time, manufacturers would be required to place hazard warnings on the twelve most dangerous chemicals. This group includes chemicals such as hydrochloric acid and sulfuric acid. After this act, these chemicals would now have to be labeled "Poison."

Perhaps the most ubiquitous warnings today are those for various kinds of pharmaceutical products. Even these warnings are a relatively recent event, as the first food and drug warnings began with the passage of the Federal Food, Drug, and Cosmetic Act in 1938. Whereas warnings today for prescription drugs often focus on long-term effects and adverse drug interactions, the emphasis of these warnings requirements was on acute toxicity. The main concern was with misbranding of products and adulteration of products. The kinds of safety and efficacy concerns that are paramount in today's warnings were simply not on the warnings agenda at that point.

About a decade later Congress extended these warnings requirements to include other products with the passage of the Federal Insecticide, Fungicide, and Rodenticide Act in 1947. For the first time, insecticides and herbicides would be required to have hazard warning labeling. In the 1960s there was a more rapid extension of these warnings policies. In 1960, Congress passed the Federal Hazardous Substance Labeling Act. This act introduced the hazard warnings vocabulary that we now take for granted. In particular, it specified the appropriate use of the human hazard signal words, "Danger," "Warning," and "Caution." In addition, this legislation also specified the first requirements that must be met for the warnings associated with substances that are flammable or radioactive.

Also in the 1960s Congress passed warnings legislation for cigarettes in 1965. Beginning in 1966, cigarettes would be required to bear an on-product warning. These warnings 
requirements were revised in 1969 and again in 1984, at which time Congress specified a series of rotating warnings that remain in place today.

Researchers in the warnings field frequently refer to the 1980s as the "right-to-know" decade. It was in that decade that the Occupational Safety and Health Administration initially imposed hazard communication requirements for dangerous chemicals used in the workplace. As part of this initiative, OSHA also required that material safety data sheets be provided for dangerous chemicals so that it would be possible to treat exposed workers appropriately. Warnings efforts of other kinds also proliferated, as the U.S. Environmental Protection Agency (EPA) began to provide information regarding toxic exposures, and there was the beginning of hazard warnings for a wide range of products, such as lawn mowers. In addition, Congress enacted a series of on-product warnings for alcoholic beverages that were patterned to a large extent on the already-existing cigarette warnings. The main difference was that alcoholic beverage warnings contained multiple warnings on each container rather than a rotating series of single warnings.

The court system also came into play with respect to hazard warnings over the past 40 years. ${ }^{26}$ Increasingly firms became liable for their failure to warn consumers adequately of the risks associated with the product. Thus, the incentives for providing warnings came not only through the market and regulatory requirements, but also from legal requirements as well.

\section{$\underline{\text { 5. Risk Assessment }}^{27}$}

\section{$\underline{5.1 \text { Objectives }}$}

\footnotetext{
${ }^{26}$ For a discussion of the development of hazard warnings legal requirements, see the American Law Institute, (1991).

${ }^{27}$ For further exploration of the risk assessment issues beyond what appears in the following section, see the European Commission (1996), National Research Council (1994), National Research Council (1996), and the U.S. Environmental Protection Agency (1988, 1996).
} 
If we assume that the policy focus is on expected costs and benefits, then the probabilities used in this calculation should be the mean risk values, as those are used in taking the expectation. Thus, the task is to calculate the expected number of adverse outcomes that will result from a policy. As the discussion below will indicate, many government agencies do not adhere to this approach but instead use upper bound estimates of the component parameters used in calculating the risk, thus yielding a risk assessment that may be in the upper tail of the distribution of what the actual risk might actually be.

The 1983 guidelines for risk assessment issued by the National Research Council (NRC), Risk Assessment in the Federal Government: Managing the Process, established standards for risk assessment but did not resolve all outstanding issues. The report claimed, as seems reasonable, that "government regulation rests on the best available scientific knowledge" (NRC, 1983, p.1). What the "best available scientific knowledge" is that should guide policy is a matter of debate. A principal benefit of the report was shifting the focus away from use of short-term, acute animal studies, which agencies formerly had used in assessing the levels of chemical exposures for which there were no-observed-effects (NOELs). Thus, the emphasis had not been on ascertaining the risk probabilities or even the dose-response relationship, but rather the exposure level at which the risk was no longer zero. More specifically, the focus was on exposure levels for which there is a "reasonable certainty of no harm." The actual NOEL value that agencies set is more stringent. After determining the scientifically valid NOEL amount, agencies then divide this zero observed risk exposure level by 100. Agencies assert that such an adjustment is warranted based on the assumption, for which there is no evidence, that humans are 10 times more sensitive to chemicals than animals, and that there is sufficient risk heterogeneity among people so that the personal risks may differ by a factor of 10 for any given 
chemical exposure. Moreover, these adjustment factors are assumed to be multiplicative. The EPA has used the NOEL value as its no-observed-adverse-effect level (NOAEL) criterion for evaluating regulatory policies.

In some instances, the policy approach to risk assessment is quite simple. The Food and Drug Administration (FDA) banned all artificial carcinogenic food additives (under the Delancy Clause) irrespective of the magnitude of the risk. Thus, the fact that the additive was artificial was the key concern, not whether the additive posed any real risks or whether the level of carcinogenicity exceeded that of naturally occurring carcinogens in the product.

At least in the case of some agencies' legislative mandates, agencies must show that the magnitude of the risk is consequential before regulation is warranted. In the U.S. Supreme Court decision dealing with the OSHA benzene regulation, the court ruled that the agency must show that the risk is "significant" before regulation is warranted. ${ }^{28}$ How large a risk must be to be termed "significant" was not specified by the Court, though the court did observe that a one in a billion cancer risk from a glass of water would not be significant.

In the mid-1980s there was further clarification of the guidelines that risk assessments should meet by the Office of Science and Technology Policy (OSTP, 1985). The risk assessment guidelines issued by EPA (1987) and other agencies were in response to these recommendations. For concreteness, the discussion below will focus on the risk assessment practices for carcinogens, as these risks play the dominant role in the estimated regulatory benefits. The agency has no guidelines for assessing the magnitude of morbidity risks so that cancer risks dominate the policy assessments.

\subsection{EPA Risk Assessment Practices}

${ }^{28}$ See Industrial Union Department, AFL-CIO v. American Petroleum Institute, 448 U.S. 607 (1980). 
EPA relies on both epidemiological studies of human populations and animal bioassay studies in assessing the risk. In most cases the agency relies on animal studies due to the paucity of sound epidemiological studies. Although EPA (1987, p. 1.6) espouses a commitment to statistical significance in this test data, such claims lack content unless one specifies the required significance level. The particular level of significance used for the test is "a matter of overall scientific judgment," according to EPA. The level selected by the agency need not, for example, be based on the usual statistical standard of a 95 percent confidence interval, two-tailed test.

The manner in which EPA combines the results from multiple studies does not place an equal weight on the various studies or weight them based on sample size. Instead, studies indicating the presence of a risk receive greater weight than do negative studies that do not indicate a risk. The result is that, for epidemiological studies, the weight of evidence "increases with the number of adequate studies that show comparable results or populations exposed to the same agent under different conditions." (EPA, 1987, p. 1.6).

EPA then categorizes carcinogens based on different groupings. Group A and Group B carcinogens are either designated human carcinogens or possible human carcinogens. Chemicals in these categories are candidates for risk assessment, as are Group C carcinogens which are possible human carcinogens. Chemicals in Groups D and $\mathrm{E}$ are not designated as human carcinogens and, as a result, are not candidates for risk assessment. For chemicals in Groups A, B, and C, EPA may then assess a dose-response relationship. These assessments typically involve extrapolations from animal studies and as a consequence assume that animal carcinogens are human carcinogens and that the evidence for animals can be extrapolated in a meaningful way to humans. The animal studies often focus on the maximum dose of a chemical that can be tolerated. Although the NRC believes that a threshold model is more plausible, EPA uses a 
linearized model which, in EPA's view, establishes "a plausible upper limit to the risk that is consistent with some proposed mechanism of carcinogenesis" (EPA, 1987, p. 1.9).

People can be exposed to risks in a variety of ways. EPA distinguishes three principal mechanisms of exposure: ingestion, inhalation, and dermal penetration. In some instances there could also be radiation risks. For each of these exposure pathways there is an assessment of the associated risks based on the chemical concentration, the duration of the exposure, and the frequency of exposure. The average daily dose (DOSE) of a chemical is given by

$$
\text { DOSE }=(\text { Concentration } \mathrm{x} \text { Ingestion Rate } \mathrm{x} \text { Duration }) /(\text { Weight } \mathrm{x} \text { Average Time }),
$$

where Concentration is the chemical concentration, Ingestion Rate is the ingestion rate of the chemical, Duration is the exposure duration, Weight is the body weight, and Average Time is the averaging time, which is a normalization factor. While EPA focused on the maximally exposed individual until 1992, since then it uses what it designates as the high end exposure estimate, which is a "plausible estimate of the individual exposure for those persons at the upper end of an exposure distribution" (EPA, 1992, p. 45).

The EPA risk assessments embody a variety of forms of conservatism. The analysis uses high-end assumptions for each of the parameters in the numerator of the DOSE calculation. The practical result is that EPA assessments of the magnitude of the risk are often at or above the $99^{\text {th }}$ percentile of what the actual value of the risk may be. ${ }^{29}$ For example, if each of the parameters in the numerator of the DOSE calculation above are at the $95^{\text {th }}$ percentile of these distributions and if the distributions are independent, then the chance that the risk is as great as the value EPA calculates is $(.05)(.05)(.05)=1.25 \times 10^{-4}$, which is far smaller than the 5 percent chance that any of the risk parameters in the calculation are as great as EPA estimates.

\footnotetext{
${ }^{29}$ For documentation of this effect, see Hamilton and Viscusi (1999) and Viscusi, Hamilton, and Dockins (1997).
} 
Numerous other forms of conservatism bias are incorporated into the analysis. For the animal studies used in calculating the dose-response rates, EPA relies on "long-term animal studies showing the greatest sensitivity" (EPA, 1987, p. 1.8), rather than average animal studies. The risk assessments also assume a level of exposure to the chemical or hazard that is typically a high-end estimate, such as the $90^{\text {th }}$ percentile of the distribution. The default exposure amounts also tend to be at the $90^{\text {th }}$ percentile, such as less than 30 years of continuous exposure to soil ingestion at a hazardous waste site. In some instances, the analysis incorporates $95^{\text {th }}$ percentile values of these parameters.

Many empirical estimates have been developed of the effect of this cascading conservatism. ${ }^{30}$ Some early studies, such as those by the Chemical Manufacturers Association (1991) and the Michigan Manufacturers Association (1993) pegged the estimated risk level as being greater than the $95^{\text {th }}$ percentile of the risk distribution. Other Monte Carlo studies, such as those by Cullen (1994) and Finley and Paustenback (1994) estimated that the EPA-estimated risk levels were greater than the $99^{\text {th }}$ percentile of the risk distribution and, in the case of groundwater contamination, beyond the $99.99^{\text {th }}$ percentile of the risk distribution. Similar results beyond the $99.99^{\text {th }}$ percentile were found in a study of assessments for 141 Superfund sites by Viscusi, Hamilton, and Dockins (1997). That study addressed only the conservatism bias in the sitespecific chemical values. Taking into account the upward biases in the dose-response relationship would push the extent of the conservatism bias even higher. The degree of bias varies depending on the policy context as well as on the chemical involved since increases in the number of species tests raise the level of bias (see Nichols and Zeckhauser (1986)).

In terms of policy effects, the conservatism practices in many respects embody the same types of influences captured by the Ellsberg Paradox. The government will place greater

\footnotetext{
${ }^{30}$ Burmaster and Harris (1993) were among the first to explore cascading conservatism biases.
} 
emphasis on dimly understood risks, compared to mean risk levels. A variety of critics, such as Nichols and Zeckhauser (1986), deplore this bias as distorting policies away from an emphasis that would produce the greatest net expected benefits. Defenders of conservatism, such as Finkel (1989), suggest that such conservatism biases offset biases in the opposite direction, such as the neglect of synergistic effects in risk assessments. However, no empirical evidence has appeared in the literature linking the extent of conservatism bias with the magnitude of any synergistic effects.

The assumption for my discussion has been that the government should be risk-neutral in assessing the expected benefits of regulations. This assumption does not imply that risk attitudes of those being protected are assumed to reflect risk neutrality or to have other properties that government entities might have. The value attached to any given benefit outcome is the individual's willingness to pay for the risk reduction, including whatever values or risk aversion that these preferences may entail. What if, however, a policy offers a 0.5 chance of preventing 10 cases of cancer and a 0.5 chance of preventing 100 cases of cancer? Should that policy be viewed as being equivalent to a policy that prevents 55 cases of cancer? These benefit assessments could differ if, for example, clustered deaths are more highly valued than an equivalent total of individual deaths, but recognizing the role of clustered deaths is a quite different matter analytically than using upper bound estimates of each parameter when doing a risk assessment.

The policy emphasis of these conservatism practices is to some extent similar in spirit to the precautionary principle, which has played a prominent role in European regulatory policies. Interpretation of what is meant by the precautionary principle is not always well defined, and this principle varies across countries, as analyzed by Gollier and Treich (2003) and by Lofstedt 
(2004). A common version of the precautionary principle is that industry must show that a chemical is safe before it can be used. Thus, the approach is analogous to the tests the FDA imposes on new drugs in the U.S., which is that they must meet tests of safety before the drug can be marketed. ${ }^{31}$ From a statistical standpoint it is not feasible to prove that a chemical is safe, but based on tests of the chemical it is possible for one not to reject the hypothesis that there is zero risk. As a practical matter, the precautionary principle permits fewer risk tradeoffs than does a policy based on a comparison of overall benefits and costs. Many European countries are now shifting away from a precautionary principle approach to a broader regulatory impact assessment that is similar in spirit to a benefit-cost test. ${ }^{32}$

\section{Valuing the Benefits of Regulation}

\section{$\underline{6.1 \text { Risk Valuation }}$}

From the normative standpoint of assessing economic benefits for government policy, the task is to assess society's total willingness to pay for the risk reduction. This formulation is a natural approach for economists, since it follows the general principles for benefit assessment for all government policy. ${ }^{33}$ Thus, to monetize the benefits from reduced fatalities once could use the VSL estimates based on fatality risk-money tradeoffs. This approach was a departure from the approach taken in tort liability cases for which the measure in cases of wrongful death is the present value of the decedent's lost earnings, net of consumption. Other factors such as noneconomic losses may enter court awards as well, but for the most part compensation for injuries is structured to serve an insurance function- to compensate the survivors after the fatality. In the case of government regulation, there is no compensation provided, but instead the

\footnotetext{
${ }^{31}$ Drugs must also meet tests of efficacy as well.

${ }^{32}$ Lofstedt (2004) reviews the evolution of these policies in detail.

${ }^{33}$ Early articulations of how Schelling's (1968) principles for private risk valuation could be extended to the public domain were written by Mishan (1971) and Zeckhauser (1975).
} 
focus is on striking the appropriate cost-risk tradeoff for purposes of risk reduction, which is a quite different matter from compensation. Thus, the difference between the courts and regulatory agencies in the approaches to valuing life stems more from the different objectives of these social institutions rather than any superiority of one measure versus another.

Although the risk-money tradeoffs reflected in willingness to pay values for risk reduction are the dominant approach in the literature, government agencies often depart from this approach by not examining total benefit values to society. Instead, the emphasis may be narrower. Rather than assessing society's willingness to pay for risk reductions affecting the total population, agencies usually use an individual risk approach. Thus, the key concern is whether any individual is exposed or hypothetically might be exposed to a risk level exceeding some threshold, such as a lifetime cancer risk of 1/100,000. Moreover, this hypothetical exposure could come from a quite different hypothetical use of the land. Justice Breyer (1993), for example, expressed his incredulity that EPA wished to clean up a hazardous waste site so that it would be safe enough for children to eat the dirt over 200 days per year instead of only just over 60 days per year. He was puzzled because the site was currently a swamp and there were no dirt-eating children in sight. The vantage point adopted for the discussion here is an assessment of society's willingness to pay for risk reduction for the total population.

The appropriate methodology for conceptualizing risk reduction benefits can be illustrated using risks to life as the example. ${ }^{34}$ If a person is willing to pay $\$ 700$ to eliminate a mortality risk of $1 / 10,000$, then the value of statistical life is $\$ 700 /(1 / 10,000)=\$ 7$ million. This value can then be used in benefit assessments and, in much the same way, these values can be constructed for other risk reduction outcomes assuming that the benefit transfer is warranted.

\footnotetext{
${ }^{34}$ For detailed reviews of this literature and an introduction to this topic, see Jones-Lee (1976, 1989), Smith (1979a), and Viscusi (1992, 1998). International evidence appears in Kniesner and Leeth (1991). Viscusi and Aldy (2003) provide the most recent review.
} 
Thus, the risk preferences, baseline risk levels, and extent of the risk reduction should be similar, or the VSL levels should be adjusted appropriately. Following the general principles of the public finance literature, one can likewise develop willingness to pay values for benefit components other than mortality risks. Such values are more appropriate than, for example, relying on medical expenses alone to value risks of injury or using travel costs to value recreational benefits of environmental amenities.

The willingness-to-pay values are for saving statistical lives, not identified lives for which the risk of death is reduced from 1.0 to zero. Jenni and Loewenstein (1997) distinguish four aspects of contexts in which the victims are identifiable. First, the deaths involve the certainty of death rather than variations in small probabilities of death. Second, identifiable deaths are often vivid and highly publicized specific individuals, generating substantial public concern. Third, the fraction of the reference group that will be saved is much greater than in a typical risk regulation program, possibly as high as 100 percent for an individual at risk. Fourth, in the case of identifiable victims, the decision is made after the lottery has been run rather than before, making it an expost decision rather than an ex ante decision.

How we conceptualize benefit values also depends on the scope of the willingness-to-pay measure. The appropriate benefit values for reducing risk are structured based on the person's willingness to pay for private benefits, but altruistic concerns may enter as well. People may be willing to pay for risk reductions for others. How and whether such valuations should enter depends on the source of the altruism. The model by Jones-Lee (1991) indicates that safetybased altruism that is independent of utility levels should be recognized as a legitimate benefit component. $^{35}$

\footnotetext{
${ }^{35}$ Interestingly, a test of the Jones-Lee (1991) model by Johanneson, Johansson, and O'Conor (1996) failed to show that respondents generally would pay a higher value for public safety than private safety improvements.
} 
In the case of morbidity effects, much of the emphasis in the literature has been on estimating the willingness to pay to reduce the risks of illness. ${ }^{36}$ The traditional human capital approach sets the benefit value equal to the opportunity costs of being sick plus the costs of mitigating behavior as reflected, for example, in medical expenses. Expenditures on behavior directed at averting risks and the disutility of being sick must also be included to have a comprehensive benefit measure. These various measures of a willingness to pay approach are generally substitutes for human capital benefit measures, not additive components. Other measures of morbidity risk benefits such as those implied by wage-risk tradeoffs in the labor market and survey valuations may produce comprehensive morbidity benefit values. ${ }^{37}$

Most quantified benefits of risk and environmental regulation are from studies of mortality risk reduction, which in turn are usually based on labor market studies of the value of statistical life. These have, of course, been efforts to impute the VSL for environmental contexts by linking housing process to pollution levels, as in Portney (1981). However, this literature is much less extensive and often involves stronger assumptions in the construction of the risk variable than do labor market studies. ${ }^{38}$ Housing has been a chief market context for analyzing price-fatality risk tradeoffs, but there have been other product market analyses as well, especially automobiles. $^{39}$

Suppose that $w(p)$ represents the market offer curve of the highest wage rate available to workers at any given mortality risk $p$. This curve is the outer envelope of firms' isoprofit curves.

\footnotetext{
${ }^{36}$ Harrington and Portney (1987) and Freeman (1993) developed much of the underlying analysis for the morbidity benefit estimation approach.

${ }^{37}$ It is interesting to note that, while one might think that only men are exposed to job risks, women face substantial injury risks as well and also exhibit wage-risk tradeoffs similar to men, as shown in Hersch (1998).

${ }^{38}$ Viscusi and Aldy (2003) provide a review of many published housing price VSL studies, which use either air pollution risks or hazardous waste risks in the analysis. An early study of VSL amounts implied by landfill risks was Smith and Desvousges (1986). Responses to natural disasters have also been the subject of scrutiny, as in Brookshire, Thayer, Tschirhart, and Schulze (1985).

${ }^{39}$ The first of many such studies showing that consumers pay more for safer cars was by Atkinson and Halvorsen (1990).
} 
Firms will offer a lower wage as the safety level increases since safety improvements are costly, and the wage rate associated with greater safety levels must be less to keep the firm on the same isoprofit curve.

Workers choose the point along this offer curve that provides them with the greatest expected utility. Here we adopt a simplified version of the formulation above as utility only depends on the worker's wages and not also on assets and health expenditures. Let the statedependent utility function $u(w)$ be the worker's utility when healthy and $v(w)$ be the utility function when the worker is injured or the bequest function in the case of fatality risks. As in the model in Section 2, these utility functions have the usual properties $u(w)>v(w) ; u^{\prime}(w), v^{\prime}(w)>0$; and $u^{\prime \prime}(w) \leq 0, v^{\prime \prime}(w) \leq 0$. Note that financial risk aversion is not required for workers to find risky jobs unattractive. For any given wage rate, increasing the risk $p$ is always undesirable since good health is preferred to ill health.

The optimizing worker will pick the point off the market opportunities frontier that provides the greatest expected utility. At this point the worker's highest valued constant expected utility locus will be tangent to the market offer curve, with the wage-risk tradeoff at this point of tangency being the worker's value of statistical life. The wage-risk tradeoff at this point is given by

$$
\frac{\partial w}{\partial p}=\frac{u(w)-v(w)}{(1-p) u^{\prime}(w)+p v^{\prime}(w)}
$$

which is a special case of the more general result in equations 3 and 4 . Thus, the implicit value of a statistical life equals the difference in utility levels between the healthy state and the ill state divided by the expected marginal utility of income. One can develop a similar analysis for other market-based tradeoffs, such as those involving product choices or housing choices, where these VSL amounts will be the same as those reflected in the labor market. 
While these tradeoffs will be pertinent for small changes in the risks of death, they will overstate the amounts that people are willing to pay for large improvements in safety and will understate how much people must be compensated for large increases in risk. The underlying influence responsible for this result is that there are wealth effects with respect to people's preferences with respect to changes in safety levels. Increases in wealth will make people more reluctant to bear risk given the assumptions above.

Empirical implementation of this approach has consisted of hedonic wage and hedonic price studies that trace out the locus of market equilibria consisting of a series of observed wage -risk combinations observed in the market. Thus, the hedonic wage equation does not trace out either the supply of workers to risky jobs or market offer curves, but rather the joint influence of these two sides of the market or the locus of observed market equilibria. The review by Smith (1979a), in particular, stresses this distinction, which has played a prominent role in the literature.

The canonical hedonic wage equation is of the form

$$
\ln w_{i}=\alpha+\sum_{j=1}^{n} \beta_{j} x_{i j}+\not p_{i}+u_{i}
$$

where $p_{i}$ is the fatality risk facing worker $i, x_{i j}$ is a series of variables $j$ pertaining to the worker i's personal characteristics and job, where these possibly include measures of workers' compensation and nonfatal injury risk, and $u_{i}$ is an error term. The median value of the implicit value of life reflected in studies throughout the world of wage-risk tradeoffs is $\$ 7$ million. ${ }^{40}$

The VSL estimates may vary considerably based on the risk preferences of the workers. The early estimates by Thaler and Rosen (1976) focused on workers facing risks about an order of magnitude greater than the national average, leading to lower estimated VSL levels than in

\footnotetext{
${ }^{40}$ A recent survey of this literature yielding this value is Viscusi and Aldy (2003).
} 
other studies. This low VSL level is what one would expect if workers who are more willing to bear risk sort themselves into the riskiest jobs.

More recent research has made an explicit attempt to examine the source of the heterogeneity in these values. Some relationships that have been borne out have not been of central interest to policymakers. For example, cigarette smokers are more willing to incur risks on the job, and people who use seatbelts regularly are less willing to bear such risks, as shown in Hersch and Viscusi (1990), Hersch and Pickton (1995), and Viscusi and Hersch (2001). Interestingly, these labor market estimates for wage-risk tradeoffs are consistent with the patterns revealed by smokers' decisions in the product market. Ippolito and Ippolito (1984) find that smokers' responses to new risk information implies a VSL level that is below the typical labor market average.

Within the context of hedonic wage and price models there could be two sources of individual differences. First, people may share the same offer curve $w(p)$ but pick different points along it. For an offer curve of the usual assumed shape, $w_{p}>0$ and $w_{p p}<0$, workers who chose lower levels of risk $p$ will be on steeper portions of the offer curve and will exhibit higher VSL amounts.

An alternative structure that alters the standard hedonic model is that workers may face quite different offer curves and be settling into separate labor market equilibria. If two groups of workers face identical offer curves, then the group incurring the greater risk should receive greater wage compensation for risk. Let there be two groups of workers $i=1,2$ who each face risk $p_{i}$ and earn wage $w_{i}\left(p_{i}\right)$. Each worker would earn the same amount for a zero-risk job, or $w_{i}(0)=0$. Suppose that $p_{2}>p_{1}$ and that the workers face the same offer curve, but that workers 2 receives a lower wage-rate. Then 


$$
w_{2}\left(p_{2}\right)-w_{2}(0)<w_{1}\left(p_{1}\right)-w_{1}(0)
$$

or, since $w_{2}(0)=w_{1}(0)$,

$$
w_{2}\left(p_{2}\right)<w_{1}\left(p_{1}\right)
$$

But under the assumption of identical offer curves,

$$
w_{2}\left(p_{2}\right)=w_{1}\left(p_{2}\right)
$$

which leads to a contradiction of inequality 16.

This generalization of the standard hedonic model facilitates an interpretation of observed empirical results. Smokers incur greater risks than nonsmokers, yet receive lower premiums for risk. Similarly, black workers face larger risks than white workers but are compensated less for these risks controlling for appropriate demographic factors and job characteristics. These findings imply that smokers face different offer curves than do nonsmokers, and black workers face different offer curves than white workers. In the case of cigarette smokers, these workers incur greater risks for less hazard pay than nonsmokers-a result that cannot occur if nonsmokers and smokers faced the same offer curve. Rather, there are separate hedonic market equilibria for different labor market groups. It is not yet clear how or whether this heterogeneity in market valuations for risk should enter the policy debate.

A more controversial current policy issue pertains to the role of individual age. In particular, should reducing risks to the lives of older people be valued less than reducing risks to the young? Older people have a lower quantity of expected remaining lifetime, but that doesn't necessarily imply that valuations peak at birth and decline steadily with age. What matters is their willingness to pay for such risk reductions. The quality of life at risk may also diminish with age, but an offsetting factor is that wealth may increase. Some standardized measures of valuation assume that there is a dimunition in the value with age. The Disability-Adjusted Life 
Year (DALY) approach in the World Health Organization study reported by Murray and Lopez (1996) assumes that the value of life years peaks in one's twenties and declines thereafter.

Similarly, straightforward adjustments in the value of life based on remaining life expectancy or discounted expected remaining years of life will also diminish the benefit values associated with reducing risks to older people.

This age-adjustment issue became a policy controversy in 2003 with respect to EPA's benefit assessments with respect to the Clear Skies initiative. Use of a lower benefit value for the elderly became known as the "senior discount" or "seniors on sale, $37 \%$ off" and was abandoned in policy calculations after substantial political outcry by senior citizen groups, such as the AARP. However, if one were to use a uniform value of life for all citizens, that would have the appearance of fairness in one sense but might also be viewed as being unfair to the young, since each year of their life would receive a lower value than each year of older citizens' lives. Use of a constant value per year of life has a fairness appeal that may be as great as using a uniform value for a statistical life. Ultimately, the issue is one that is not a question of fairness or symmetry in valuation but how the willingness to pay to reduce fatality risks varies with age.

From an economic theory standpoint, the value of statistical life should eventually decline over the life cycle. Models such as those by Shepard and Zeckhauser (1984) and Johansson (2002) have shown that if capital markets are imperfect, then the value of life will rise and then fall over the life cycle. ${ }^{41}$ These models also demonstrate that the value of statistical life at any given age is dependent on current and future consumption levels. Because consumption rises then falls over the life cycle, one should expect a similar temporal pattern in the variation of the value of statistical life with age.

\footnotetext{
${ }^{41}$ Using a different framework, Rosen (1988) predicts that VSL will decline with age.
} 
The two approaches to estimating changes in values of statistical life have been to use survey estimates of the willingness to pay of risk reduction and estimates derived from market data to analyze changes in the implicit value of statistical life with age. The willingness-to-pay survey study by Jones-Lee (1989) found a declining value of life with age, whereas the more recent survey study by Krupnick et al. (2002) found a much flatter relationship, though this study considered a narrower age band than did Jones-Lee (1989). Many market-based studies of agerelated variations in workers' value of statistical life showed a steadily declining relationship, but these early studies tended to use average risk levels by industry, with no accounting for age variations in jobs. ${ }^{42}$ More recent estimates using age-dependent risk measures ${ }^{43}$ and analyses that take into account consumption variations over the life cycle ${ }^{44}$ each show that the value of statistical life displays the inverted-U shaped pattern predicted by most theoretical analyses, but that the decline in the value of life with age is not steep. Older workers are, for example, much less willing to incur fatality risks than are workers in their early twenties.

To see how age-related difference in the value of life can affect benefit assessments consider the different estimate of the mortality reduction benefits for the U. S. EPA Clear Skies Initiative, which are reported in Table 1. Using a constant VSL of \$6.1 million, EPA found that the bulk of the estimated benefits of the policy are for senior citizens, whether the analysis is based on long-term exposure or short-term exposure risk estimates. If one applies the senior discount of 37 percent used in an illustrative analysis by EPA, estimated benefits drop by a bit less than that proportion given that most of the mortality reduction benefits are concentrated among those age 65 and older. If, however, one uses VSL amounts that are reflective of the VSL

\footnotetext{
${ }^{42}$ These studies are reviewed in Viscusi and Aldy (2003).

${ }^{43}$ See Aldy and Viscusi (2004), which uses fatality risk and injury risk data by age.

${ }^{44}$ Kniesner, Viscusi, and Ziliak (2004) incorporate consumption into the wage equations.
} 
levels based on one set of estimates of age differences revealed through workers' job choices, the estimated benefits are roughly the same as in the case without age adjustments. ${ }^{45}$

\section{$\underline{6.2 \text { Contingent Valuation and Survey Methods }}$}

Reliance on market evidence for imputing private valuations is generally preferable to willingness to pay survey questions when reliable market data are available. However, there are many situations in which meaningful market estimates are not feasible. Perhaps the chief example in which such survey methods are used is that for valuation of the losses associated with natural resource damages, such as the harm caused to natural resources.. There are also other less dramatic contexts in which survey methods are used to obtain benefit values. Obtaining survey estimates of society's willingness to pay may be the best available benefits approach to assess benefits such as improved visibility at the Grand Canyon, the discomfort of respiratory illnesses, or the value of saving an endangered species. Indeed, to the extent that there is a concern with non-use values or passive use, then use of some kind to survey approach is the only viable technique for deriving empirical estimates of the benefits.

Survey techniques such as contingent valuation methods, stated preference methods, and conjoint analysis serve as the mechanism for obtaining such valuations. These methods have been highly controversial, and in part because of this controversy, considerable attention has been devoted to the development of criteria that reasonable surveys should meet. ${ }^{46}$ Thus, while use of stated preference methods of various kinds may not be preferable to market-based estimates when they are available, for many environmental benefits these approaches represent the only technique for developing meaningful benefit estimates. While a comprehensive review

\footnotetext{
45 These particular age variations in VSL are estimated by Kniesner, Viscusi, and Ziliak (2003) using a hedonic wage model that incorporates life-cycle consumption patterns into the analyses.

${ }^{46}$ For an introduction to many of the controversies surrounding contingent valuation, see Diamond and Hausman (1994). Hanemann (1994) and Portney (1994) have a more positive view of developing contingent valuation techniques to provide sound benefit estimates.
} 
of these issues would be quite lengthy, there are several key concerns that must be addressed for such surveys to have validity.

Because these surveys ask people to engage in a hypothetical market transaction, the respondent must understand the good being valued, and the payment mechanism must be realistic. If people treat the survey questions as pertaining to hypothetical interview money and do not recognize that there is a real economic opportunity cost, then valuations will be too great.

A long-term concern in the economics literature has been that people might misrepresent their preferences if a public good is being valued. Such strategic misrepresentation has not proven to be a major problem and can be addressed by, for example, structuring the survey in terms of votes on a referendum and imputing the tradeoff rates statistically using, for example, a random utility model. A more important practical problem is demand effects, as highlighting an environmental amenity in the survey may make respondents willing to have greater stated preferences for that good than if they took into account possible alternative uses of these funds.

In an effort to address the potential biases of hypothetical choice contexts, researchers also have devised a series of rationality tests that surveys should meet, many of which mimic the usual economic criteria for rational consumer choice. Respondents' willingness to pay should increase with the amount of the good provided. Thus, policies that reduce the risk of harm to a greater extent should be more highly valued.

In contrast, some surveys have shown that people are willing to pay the same amount to save 100 birds as to save 10,000 birds. $^{47}$ This lack of responsiveness to the amount of environmental good may arise because people suffer from embedding effects. ${ }^{48}$ Thus, respondents in each instance may view their response as simply a vote of support for the

\footnotetext{
${ }^{47}$ See Desvousges (1993) for analysis of the insensitivity of valuations to the extent of environmental improvement. ${ }^{48}$ This term characterizing the limitation of contingent valuation studies was coined by Kahneman and Knetsch (1992).
} 
environment more generally rather than distinguishing the quantity of the good. A basic rationality test that should be met is that across subjects, willingness to pay values should increase as the amount of the good provided increases. However, this increase in valuations need not be linear, so that people shouldn't necessarily value saving 10,000 birds by 100 times more than they value saving 100 birds. There may be a rapidly diminishing marginal willingness to pay that will generate similar values from an accurate assessment of individual preferences. Another rationality check is that for tests within subjects, the preferences should satisfy the usual economic rationality criteria such as transitivity.

When there are multiple goods involved, there are rationality tests pertaining to the scope of the good provided. If a policy saves birds and fish rather than fish alone, then the willingness to pay for that policy should be greater. This test is simply the analog of the test for single dimension goods in that people should prefer more of the good to less.

In some instances researchers have used a currency other than dollars for the valuation. Thus, for example, respondents might be asked to choose between a reduction of risks of automobile accidents against reduced risks of cancer from environmental pollution. ${ }^{49}$ Such tradeoffs can address the problems that might arise if people treat survey interview money as having little value and may also be useful in enabling respondents to compare two commodities that are both non-monetary and involve probabilistic goods. These comparisons of two goods on the same nonmonetary dimension, such as comparing reductions in auto accidents to environmental improvements, can also overcome respondents' reluctance to monetize environmental goods. In addition, if the task requires valuing small risks that would otherwise present risk denominators that were difficult to process, such as a risk of $1 / 100,000$, then these

\footnotetext{
${ }^{49}$ Magat, Viscusi, and Huber (1996) use an automobile fatality accident risk metric to value fatal and nonfatal cases of cancer.
} 
probability values could be made comparable for the two risks being compared so as to reduce the cognitive demands of the valuation task.

These methodologies remain in the developmental stage, though much progress has been made since the contingent valuation debate was launched over a decade ago. No general conclusions are possible regarding the validity of various stated preference approaches. However, it has become increasingly apparent that survey methods often can serve a useful function for assessing many categories of benefits that have no market-based valuations. In addition, even though the validity of these studies must be assessed on a case by case basis, a series of validity tests has been developed that will provide a degree of quality control.

Survey methods are especially useful when market-based estimates are either unavailable or unstable. Thus, these techniques have even proven useful in estimating VSL levels, which is the context in which labor market estimates have been particularly well developed. However, these estimates have not shown the same pattern of stability using data from the U.K. The labor market studies for the U.K. have yielded wildly varying estimates. ${ }^{50}$ As a result, policymakers assessing the benefits of transport safety policies rely on survey values such as those elicited in the willingness to pay study of rail travel and auto travel undertaken by Jones-Lee (1989) and Jones-Lee, Hammerton, and Philips (1985). The VSL estimates derived from these surveys are more in line with U.S. labor market VSL amounts than are the U.K. labor market studies. ${ }^{51}$

\section{Benefit-Cost Analysis}

The economic efficiency test for regulations is that at the minimum the benefits exceed the costs and that ideally one should maximize the spread between benefits and costs. ${ }^{52}$ Consider

\footnotetext{
${ }^{50}$ These variations are surveyed in Viscusi and Aldy (2003).

${ }^{51}$ They also yield results similar to those in U.S. survey studies, which are reviewed in Viscusi (1992).

${ }^{52}$ Equity concerns often enter policy debates as well, especially with respect to environmental policies' effects by race. See Hamilton (1995) for examination of these issues, as well as Hamilton and Viscusi (1999).
} 
a mortality-reducing regulation that only has effects in the current period. Let the cost of the regulation be $c$, the extent of the average mortality risk reduction be $s$, the number of people affected be $n$, and the value of statistical life be $v$. Ideally, the policy should maximize the spread between benefits and costs, or maximize the difference snv-c. Regulators are seldom held to this standard, but instead must meet the requirement that the benefits exceed the costs, or

$$
s n v>c .
$$

This seemingly innocuous test has a strong justification, but is not always compelling. The caveats regarding benefit-cost tests in the public finance literature generally focus on concerns relating to the Hicks-Kaldor compensation criteria, which are that the gainers aren't always compensating the losers, in which case the policy is not particularly attractive to those whose welfare is reduced. The Hicks-Kaldor potential compensation criterion is not as compelling as it would be if such compensation actually were paid.

The departures from the benefit-cost approach in the practice of risk regulation policy are much more diverse. The transportation safety regulations are a notable exception in that they meet a benefit-cost test. The benefit-cost test can be rewritten as

$$
s>\frac{c}{n v}
$$

or the risk reduction must exceed the policy cost divided by the population affected multiplied by the value of statistical life. In contrast, risk policies are often governed by the test

$$
s>s^{*},
$$

where $s^{*}$ is a critical risk probability triggering regulation. In the case of EPA hazardous cleanup efforts, a value of $s^{*}$ above 1/10,000 makes cleanup mandatory, and a value of $s^{*}$ such that $1 / 10,000 \geq s^{*} \geq 1 / 100,000$ puts cleanup in the discretionary range. Sites posing lifetime risks to at least one current or hypothetical future citizen of magnitudes below 1/100,000 are not 
cleaned up. Note that the population size $n$ does not enter consideration. Thus, policies are often based on criteria that are characterized as the individual risk approach, in which risks to a single individual drive the policy decision. In contrast, the more comprehensive benefit-cost test takes what has been termed the population risk approach in which the number of people whose risks are being reduced is of consequence.

The benefit-cost test can be rewritten in cost-effectiveness terms as

$$
\frac{c}{s n}<v,
$$

or the cost per life saved is less than some critical value $v$. This formulation is useful in characterizing the relative performance of regulations, as will be done below. It can also be used in assessing regulatory performance in instances in which one is perhaps reluctant to commit to a particular value of statistical life $v$.

Justice Breyer (1993) uses the approach of equation 21 in the following manner. Efficient risk reduction will lead people to equate the cost per unit risk across different areas of risk reduction activity. Support for a regulation that would impose an inordinate cost per expected life saved, such as an inefficient asbestos regulation, could only be justified if one were willing to spend an additional $\$ 20,000$ on a car that was marginally safer. In effect, Breyer contrasts the risk-money tradeoff implied by inefficient regulatory policies with hypothetical but realistic private choices to demonstrate their undesirability.

This approach simply articulates the theoretical underpinnings of the market-based methodologies used to estimate $v$. These values reflect the price-risk or wage-risk tradeoff estimates based on market decisions, thus establishing $v$ empirically. Breyer instead uses the same comparison implied by equation 21 above, except he does so by indicating a government risk-cost tradeoff that dwarfs people's sense of what $v$ is in their own decisions. 
Once the element of multiple time periods is introduced, the benefit and cost components can have a time dimension $t$. Letting $r$ be the rate of discount, the policy benefit-cost test for efforts that impose an initial costs $c$ at time zero and generate a benefit stream over time is

$$
c<\sum_{t=0}^{\infty} \frac{p_{t} n_{t} v}{(1+r)^{t}}
$$

where the value of statistical life $v$ does not vary over time though it could if there are, for example, important income effects.

This condition can be rewritten in a form that provides a convenient index of policy efficacy. In single period contexts the criterion for attractive policies is that the cost per expected life saved be less than some critical value $v$. With multiple periods this requirement is that the cost per discounted expected life saved be below the VSL, or

$$
\frac{c}{\sum_{t=0}^{\infty} \frac{p_{t} n_{t}}{(1+r)^{t}}}<v .
$$

In addition to the usual controversies over the appropriate rate of discount, there are also debates over what the discount rate should be, particularly in the case of environmental policies. Some analysts have suggested that there be no discounting at all for environmental benefits. This practice is not only inconsistent with people's revealed rate of time preference in market decisions; it will also lead to anomalies. Any environmental damage that will be inflicted at a level of a dollar per year forever will swamp any finite benefit estimate. Thus, there could never be a policy justification for making extinct a not particularly interesting plant species, because doing so would impose infinite environmental costs, even if there were very large but finite benefits, such as completely eradicating all current causes of premature mortality. In addition, in a world without discounting, if the costs of the policy decrease over time due to technological 
progress, it will always be desirable to postpone taking action, because the present value of costs will be less if decisions are deferred, and the infinite benefit stream will be unaffected.

The discounting controversy that has achieved greater prominence pertains to the treatment of future generations. Some observers, such as Revesz (1999), have suggested that benefits to future generations not be discounted. ${ }^{53}$ What is meant operationally by this proposal is unclear. Suppose that the current generation ends at time $T$ and the future generation begins at time $T+1$. How is the value of $T$ determined? Is it the life expectancy of the average voter now alive, the life expectancy of the people now being born, or some other value? Once $T$ is determined, does a policy of not discounting benefits to future generations imply that the policy criterion is

$$
c<\sum_{t=0}^{T} \frac{p_{t} n_{t} v}{(1+r)^{t}}+\sum_{t=T+1}^{\infty} p_{t} n_{t} v
$$

or

$$
c<\sum_{t=0}^{T} \frac{p_{t} n_{t} v}{(1+r)^{t}}+\sum_{t=T+1}^{\infty} \frac{p_{t} n_{t} v}{(1+r)^{T+1}} ?
$$

In the former instance, the failure to discount benefits to future generations at all implies that saving any expected lives in future generations receives a greater weight than saving a life for the current generation for every period other than time zero. The second formulation eliminates this problem by ending the discounting based on a discount factor linked to a time $T+1$. However, there remains the problem that permanent risk reduction effects for future generations will receive an infinite value, thus swamping effects for the current generation. There will also be inequities within future generations that will not be consistent with the policies they will select themselves. Thus, decision makers at time $T+1$ will discount benefits at time $t^{\prime}\left(t^{\prime}>T+1\right)$ by

\footnotetext{
${ }^{53}$ For a general treatment of the economics of discounting fatality risk benefits, see Cropper and Portney (1990). Horowitz and Carson (1990) present empirical evidence on respondents' willingness to discount statistical lives.
} 
$1 /(1+r)^{t^{\prime}-T-1}$. However, if there is no discounting for future generations when decisions are made now, this discount factor with respect to delays within the future generation will be 1 .

Discounting also has come under fire with respect to discounting of physical units of environmental amenities. However, what is being discounted is not the physical benefits but rather society's willingness to pay. Thus, it is entirely appropriate to calculate a cost per discounted expected life saved as was done in equation 23 above and compare it to the value of $v$.

Equivalently, one could convert the cost value to its terminal value at the time the benefits are generated rather than discounting lives. Thus, if $z$ is the expected number of lives a policy costing $c$ saves after a 10 year lag, one could calculate the cost per discounted life saved as $c /\left(z /(1+r)^{10}\right)$, or instead calculate the terminal value of the cost, $c(1+r)^{10}$ and divide that by the undiscounted value of $z$. In each case, the cost-risk tradeoff value is $c(1+r)^{10} / z$.

Other standard controversies surrounding benefit-cost tests are that benefit values for goods not traded in the market will be undervalued and costs will be overestimated. The concerns about undervaluing environmental amenities and similar commodities largely predate the development of survey valuation methods, which enable researchers to develop benefit estimates that many view as too high rather than too low. The cost underestimation issue is one of practical policy implementation and raises concerns as to whether policymakers can learn from past biases in cost estimation, should they exist. Companies, for example, have an incentive to overestimate compliance costs, but this self-interest is known to government regulators.

The overall performance of regulations with respect to the cost per life saved is reflected in the statistics in Table 2. This table, which is based on the work of the Office of Information 
and Regulatory Affairs at the U.S. Office of Management Budget, was reported by Morrall (2003). The table draws on the results in Hahn, Lutter, and Viscusi (2000), which presented estimates of the net costs per life saved, where the costs are net of benefits other than the lives saved. Table 2 lists the opportunity cost per life saved for a large series of major government risk and environmental regulations.

Such compilations of costs per life saved have become controversial in the past, in part because the calculations sometimes have been misunderstood. Consequently, it is worth emphasizing several aspects of the way in which this table is constructed. First, the measure of regulatory efficacy is the opportunity cost per life saved. This figure parallels the more conventional cost per statistical life saved calculation, except that the opportunity cost of funds is brought to the future at a seven percent rate of interest rather than discounting the number of lives saved back to the current period. As was indicated in the discussion above regarding equation 23 , this approach is mathematically equivalent to a cost per discounted life saved approach.

The regulations that appear in Table 2 appear in order of the opportunity cost per life saved. The most cost-effective regulations are at the top of the table, and the least cost-effective regulations are at the bottom. In every instance, it should be emphasized that the scale of the regulatory effort also is influential in affecting the total benefits less costs of these efforts. Thus, the ranking is in terms of the rate at which benefits are generated relative to the cost, but are not necessarily in order of the overall net benefits to society.

In an earlier version of this table prepared by Morrall (1986), the table listed final, proposed, and rejected rules, and indicated on the table the status of each rule. The tabulation in 
Table 2 of 76 regulations focuses only on final regulations and does not include rejected or proposed regulations.

What is perhaps most striking about this table is the difference across agencies in the relative cost-effectiveness of their efforts. For agencies within the U.S. Department of Transportation - the Federal Aviation Administration (FAA) and the National Highway Traffic Safety Administration (NHTSA)—all regulatory proposals meet a benefit-cost test in that none of them imposes an opportunity cost per life saved in excess of $\$ 4.4$ million. In contrast, many of the regulations at the bottom of the table impose inordinately high costs per life saved. This distribution is largely attributable to the difference in the agencies' legislative mandates, as the requirements for EPA, OSHA, and FDA policies are often in terms of promoting health and safety alone, without requirements that the cost be considered, and in some cases with requirements that cost not be considered.

While the legislative mandates are often structured quite narrowly, agencies may often interpret them in a more flexible manner. There may be some informal balancing of costs and benefits under different guises, such as a stated desire not to cause adverse effects on employment. The EPA pesticide regulation program strikes such a balance despite more uncompromising stated policy objectives, though Cropper et al. (1992) estimated that the cost per case of cancer avoided by this program had a value of $\$ 35$ million, which is still quite high.

Suppose for concreteness we take the $\$ 7$ million value per statistical life as the reasonable reference point for efficient levels of expenditure on saving statistical lives. Using that benchmark, the regulations that pass a benefit-cost test end with the radionuclides/uranium mines regulation, and the group of regulations that fail a benefit-cost test begins with the roadway worker protection regulations. There are many regulations on the table that cost in excess of 
$\$ 140$ million per statistical life saved. The most expensive regulation listed is the EPA solid waste disposal facility criteria, which cost $\$ 100$ billion per statistical life saved. The total budget for such regulations is of course less than $\$ 100$ billion, as astronomical cost per life saved figures such as this emerge when dividing reasonably substantial cost amounts by very small mortality risk reductions.

The differences in the efficacy of government regulation are embodied in what Breyer (1993) popularized as the 90-10 Principle. This hypothesis is that society spends 90 percent of its costs to address the last 10 percent of the risk. Put somewhat differently, the first 10 percent of the costs will eliminate 90 percent of the risk. While this principle of decreasing marginal efficacy of regulatory costs is impressionistic and not based on empirical evidence, it is consistent with the widely differing cost-effectiveness of risk regulation policies. Thus, reallocations of expenditures toward policies at the top of Table 2 would save more lives at considerably less cost. ${ }^{54}$

From the standpoint of using society's resources in the most cost-effective way to save lives, uses of the funds in contexts other than those involving government regulation might provide a higher return in expected lives saved per dollar expended. Tengs et al. (1995) present an inventory of hundreds of estimates of costs per life saved from medical contexts. Analyses of these interventions may not be comparable to the regulatory assessments by Morrall (1986, 2003), who maintains consistent assumptions so that costs per life saved are comparable across regulations. Nevertheless, the Tengs et al. (1995) compilation highlights the often dramatic cost beneficial character of much medical care. Childhood immunizations, for example, are extremely valuable in terms of being a low cost mechanism for saving lives.

\footnotetext{
${ }^{54}$ Similarly, targeted allocations within programs would have the same benefits. Hamilton and Viscusi (1999) show for a large sample of Superfund sites that 10 percent of the expenditures would eliminate over 99 percent of the cancer risk.
} 


\section{Risk-Risk Analysis}

The existence of tradeoffs involving different kinds of risks frequently arises in regulatory situations. Perhaps the classic example is that involving FDA approvals for new prescription drugs, which focuses on the safety and efficacy of new drugs. The agency must balance two different kinds of health risks. FDA may reject a drug that is safe and effective, thus committing a Type I error. Alternatively, there is the risk that the agency will approve a drug that is not safe and effective and may in fact be dangerous, thus committing a Type II error. Note that both Type I errors and Type II errors impose health costs on the population. However, the risks differ in character. Type II risks are errors of commission and Type I errors are errors of omission. Because blame and adverse repercussions for the agency are generally higher for Type II errors, FDA places greater weight on these errors. From an economic efficiency standpoint, the risks should be treated symmetrically. The existence of such risk-risk tradeoffs is not restricted to FDA approvals but arises in a wide variety of regulatory situations.

\section{$\underline{8.1 \text { Health Effects }}$}

The existence of regulations that impose extremely large costs per life saved not only is a waste of economic resources, but also may harm individual health. A major empirical pattern that has been extremely well-documented is that greater affluence increases life expectancy and other measures of health status. Thus, to the extent that government regulations impose costs that divert funds away from expenditures that could have been made for health-enhancing commodities, such as better health care and safer products, pursuing such regulatory policies may have a counterproductive effect on overall health.

Some early estimates of this linkage focus on simple regression models linking income with mortality, yielding estimates that the level of income loss that would be sufficient to lead to 
the loss of one statistical life is under $\$ 10$ million. Results such as these were cited by Judge Stephen Williams in suggesting that OSHA regulations may be inefficient and may be counterproductive in terms of their effect on health. ${ }^{55}$ Results of such studies linking mortality to health status are complicated by the fact that the relationship is two-directional, as better health status also affects one's earnings. Moreover, the estimates of the income loss that would lead to the loss of one statistical life using this methodology were very close to estimates of the value of saving a statistical life, so that an expenditure of $\$ 7$ million to save a statistical life would be almost entirely counterproductive in that this risk reduction expenditure would lead to a diversion of resources from a bundle of consumer expenditures that otherwise would have saved almost one statistical life. ${ }^{56}$ Early estimates, such as those by Keeney (1990), tended to be low. A major difficulty has been controlling for the simultaneity of income and health. This was done by Chapman and Hariharan (1994).

The various approaches to estimating risk-risk tradeoffs can be reconciled by formalizing the theoretical linkage between the value of statistical life from the standpoint of saving lives as well as the level of income loss that leads to the loss of a statistical life. Even if the regulation does not pass a benefit-cost test, at the very minimum it should enhance safety or lead to $\Delta \pi>0$ in terms of our earlier notation in which $\pi$ is the probability of survival. The components of $\Delta \pi$ consist of the marginal effect of regulation-induced safety level effects $\Delta s$ on the value of $\pi$, the marginal effect of $\Delta s$ in decreasing health investments, and the effect of the financial cost $\Delta y$ of regulation on risk due to the positive income elasticity of demand for health-related expenditures.

\footnotetext{
${ }^{55}$ See International Union, UAW v. OSHA, $938 \mathrm{~F} 2 \mathrm{~d} 1310$ (DC Cir 1991) at 1326 (Williams concurring). The U.S. General Accounting Office (1992) also examined the policy implications of risk-risk analysis for OSHA rulemaking. Other early treatments of these issues include Keeney (1990); Graham, Hung-Chang, and Evans (1992); Lutter and Morrall (1992); and Viscusi (1994).

${ }^{56}$ These estimates for the U.S. are similar in magnitude to those found for Sweden by Gerdtham and Johannesson (2002), whose risk-risk analysis estimated that the income loss that would lead to the loss of one statistical life ranged from $\$ 6.8$ million to $\$ 9.8$ million.
} 
The condition that regulations promote safety is that

$$
\Delta \pi=\frac{\partial \pi}{\partial s} \Delta s+\frac{\partial \pi \partial h}{\partial h \partial s} \Delta s+\frac{\partial \pi \partial h}{\partial h \partial y} \Delta y>0 .
$$

After some manipulation of equation 26, it can be shown that government regulations will have a net risk-reducing effect on the risk level if

$$
\begin{aligned}
& \text { Average Regulatory } \quad<\quad \text { Marginal Value of Life } \\
& \text { Cost per Life Saved Marginal Propensity to . } \\
& \text { Spend on Health }
\end{aligned}
$$

The key concern is consequently what the magnitude of the term on the right side of this inequality is. Clearly the average regulatory cost per life saved that could be expended before regulations become counterproductive is quite closely linked to the value of statistical life. The critical cutoff for cost-effective regulations is the value of statistical life divided by the marginal propensity to spend on health. If the calculation includes only favorable health expenditures that are mortality-reducing in calculations pertaining to this denominator, as in Viscusi $(1994,1998)$, the level of expenditure of regulations before these efforts become counterproductive is estimated to be $\$ 70$ million if the value of statistical life is $\$ 7$ million. However, if this calculation also recognizes the income relatedness of expenditures that harm individual health, such as those pertaining to smoking, drinking, and lack of exercise, as in Lutter, Morrall, and Viscusi (1999), then the level of expenditures before regulations become counterproductive is a cutoff level under $\$ 30$ million. Thus, for this cutoff level, all regulations at or below the asbestos/construction regulation appearing in Table 2 combine a low level of expenditure with such a modest direct safety enhancing effect that on balance these regulations are harming individual health rather than benefiting health. Considering a set of regulations similar to those in Table 2, Hahn, Luttter, and Viscusi (2000) present a set of estimates of the net effects of regulations on risk levels that reflect the risk-risk tradeoffs involved. 
The use of protective equipment, such as seatbelts, reduces the risk to the wearer, thus providing potentially valuable private benefits. Blomquist (1979) uses evidence from the tradeoff users of seatbelts made between disutility (time and discomfort) and safety to derive an estimate of VSL in this context that is not unlike labor market estimates. From a policy standpoint, Arnould and Grabowski (1981) estimate that the private risk reduction benefits from seatbelts offset the costs so that failure to buckle up represents a market failure. Indeed, recent estimates by Levitt and Porter (2001) indicate that seatbelts save lives at a cost of $\$ 30,000$ per statistical life as compared to $\$ 1.8$ million for air bags.

Such estimates take into account only the risk reduction aspect of seatbelts and ignore potentially offsetting behavioral consequences. Safety regulations may also not have their intended effects if people reduce their precautionary behavior in response to the regulation. Thus, there may be a moral hazard problem with respect to regulations that enhance the safety level associated with any particular level of precautionary behavior.

Two different mechanisms for such a response have been distinguished in the literature. In his analysis of individual responses to seatbelt regulations, Peltzman (1975) hypothesized that the effect of seatbelts in reducing the risk level would be to diminish the level of care taken by drivers, thus dampening and possibly eliminating the safety reduction benefits of seatbelts. In Viscusi $(1984,1992)$ the hypothetical mechanism influencing the performance of safety caps stemmed from a misperception of the extent to which safety devices were protective. Thus, if people believe that safety caps on medicine made these products childproof rather than simply more difficult to open, they would become more lax about the extent of safety precautions than they would be had they been aware of the actual level of risk reduction produced by safety caps. 
We can illustrate these relationships with a simple model. Let $f$ be the stringency of the government policy as reflected in the technological safety-related requirements. The other determinant of the accident risk is the individual's safety-related effort $e$. Thus, we have an overall accident risk probability function $p(e, f)$, where higher levels of both $e$ and $f$ reduce the accident risk but at a diminishing rate. If an injury occurs, the accident imposes a monetary equivalent loss of $z$. Taking safety precautions does, however, impose a cost on the individual given by $v(e)$, where both $v^{\prime}, v^{\prime \prime}>0$. The individual in this model, in which effort and harm have monetary equivalents, has an income level of $y$. Suppose that the government's choice of the regulatory stringency $f$ is given, and that the individual chooses the level of safety-related effort $e$ to

$$
\operatorname{Max}_{e} Z=[1-p(e, f)][i-v(e)]+p(e, f)[I-v(e)-z]
$$

or

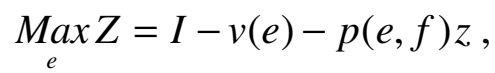

leading to the first-order condition

$$
-p_{e} z=v_{e}
$$

The marginal reduction of the loss due to extra safety-related effort is equated to the marginal disutility of effort.

If the stringency of government regulation is increased, the safety-related effort will decline, or

$$
\frac{d e}{d f}=\frac{-p_{e f} z}{p_{e e} z+v_{e e}}<0
$$

if we assume that $p_{e f}>0$ as in previous analyses of this issue. 
The extent of the behavioral response is an empirical issue. On a theoretical basis the level of precautions should decrease, but whether the offsetting behavior will lead risk levels to be greater than would prevail had there been no regulation can only occur if one imposes strong restrictions on functional forms. If, however, people overestimate the efficacy of the regulatory policy $s$, then there is greater potential for a counterproductive effect.

Empirical evidence for the consequence of seatbelt regulation has not been conclusive. The effect of seatbelt regulations has been controversial, as Peltzman (1975) found that there was no evidence that the advent of seatbelts had a beneficial effect on safety. Similarly, a comprehensive review of the evidence and new empirical work by Blomquist $(1988,1991)$ found that use of seatbelts led to increased deaths among motorcyclists and pedestrians, which is consistent with the behavioral response model in which drivers increase their driving speed if they are protected by seatbelts. Keeler (1994) found that urban speed limits reduced fatalities, but rural speed limits did not, which he hypothesized might be the result of offsetting behavior. More recent evidence by Cohen and Einav (2003), however, failed to find evidence of the offsetting behavior. ${ }^{57}$

The empirical evidence regarding the effect of safety caps on child poisoning is more clear-cut, largely because it derives from a situation in which people erroneously believe that the safety devices are more effective than they actually are. The majority of aspirin child poisonings have been from safety-capped bottles even to a greater extent than would be predicted by the safety cap share of aspirin sales. Related products, such as acetaminophen, exhibited an increase in risk levels once safety caps were introduced as consumers apparently became more lax about the need to be more protective about medicines generally.

\footnotetext{
${ }^{57}$ For additional evidence along these lines that is more supportive of seatbelts, see Crandall, Gruenspecht, Keeler, and Lave (1986).
} 


\section{The Enforcement and Performance of Government Regulations}

The efficacy of government regulations in enhancing health and safety is reflected to a large extent in the cost-effectiveness statistics presented in Table 2. There have been considerable expenditures made that were expected to have modest effects on risk reduction under three key assumptions. First, the analyses assume that there will be no offsetting behavioral responses that diminish the assumed efficacy of the health and safety standards. Thus, drivers for example do not become riskier in their driving habits if they use seatbelts. Second, the risk-risk effects that arise from the fact that regulatory expenditures divert our resources from other health enhancing expenditures are not taken into account. Third, the analyses assume that there will be full compliance with the regulatory standard. With regulations that have substantial costs of compliance, it is by no means ensured that firms will make the requisite expenditures to achieve compliance.

Because enforcement efforts are costly, it is not generally socially optimal to have enforcement efforts that induce full compliance. The economic theory of enforcement began with the analysis of criminal behavior by Becker (1868) and continued with a series of papers by Polinsky and Shavell $(1979,1992,1994)$ and others. As an illustration of the pertinence of the economic analysis of enforcement to regulatory contexts, consider the work by Cohen (1987, 1992), who develops models of optimal enforcement activity that demonstrate the tradeoffs involved for environmental policy. The social welfare maximizing government agency in the Cohen (1987) model minimizes total social costs, which include environmental damages, cleanup or recovery costs, private-resource costs, preventive expenditures, monitoring expenses, and detection expenses. The optimizing regulator will set the penalty function to induce the socially optimal level of safety. With perfect enforcement, the expected penalty equals the 
expected environmental damage plus cleanup cost. However, the probability of detection is not 1.0 because monitoring and detection will not be perfect given the costs associated with enforcement, so that the penalty should be increased accordingly to provide appropriate incentives.

In practice, non-complying firms often face very low regulatory penalties coupled with a small probability of detection. To examine the firm's incentives for compliance, consider a model for analyzing whether firms comply with regulations follows the same general approach as economic models of crime, which are examined in Chapter _. Risk-neutral firms will choose to comply with the regulation if the costs of compliance are less than the expected costs of noncompliance, or

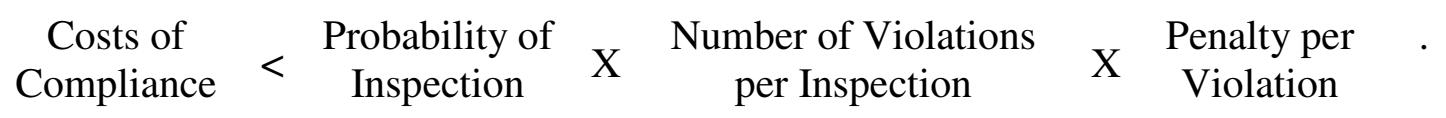

Whether firms find it desirable to comply with a regulation depends not just on compliance costs, which tend to be high, but also on the regulatory enforcement approach, which varies considerably by agency. The Occupational Safety and Health Administration (OSHA) has received the most attention for inadequate compliance with its regulations as the probability of inspection for any given firm is under 1/100 annually. If the firm is inspected, the inspectors generally identify a few violations and impose penalties that are dwarfed by market incentives for safety. The inspection strategy for EPA water pollution regulations requires annual inspections as well as the filing of monthly discharge monitoring reports, leading to much greater incentives for compliance. In the case of mass marketed consumer products, such as lawn mowers and prescription drugs, compliance is readily monitorable.

The performance of regulatory policies has varied substantially due to differences in the efficacy of the different approaches as well as differences in enforcement. Several studies have 
estimated effects of the broadly based OSHA inspections on safety, which were found to be zero or small in most studies. ${ }^{58}$ When these inspections are targeted strategically by the agency, the performance may fare better. Inspections that are undertaken only after the agency inspects the on-site incident records have led to lower reported injury rate levels. ${ }^{59}$ EPA water pollution standards have had a much better track record, as has the EPA phasedown of lead in gasoline. The lead phasedown regulation is particularly noteworthy in that it is a success story in terms of having costs below the economic benefits. In other instances, such as seatbelt regulations and safety caps, the behavioral response to regulations has muted or offset the beneficial effect of the safety-enhancing technology.

\section{Conclusion}

Economics plays a central role in the analysis and development of risk and environmental regulations. The sources of market failure in this arena provide the impetus for an active role of regulatory policy. The economics literature on informational failures, externalities, and irrational choice often use risk and environmental contexts as the paradigmatic examples of these market failures.

An economic analysis of the regulatory policy is a required component of the policy development process in the U.S., and preparation of regulatory impact analyses for prospective regulations is increasingly becoming the norm throughout the world. While economic assessments of benefits and costs may inform regulatory policy decisions, the restrictive legislative mandates of regulatory agencies often require that the agency adopt objectives other than a comprehensive balancing of benefits and costs.

\footnotetext{
${ }^{58}$ See Viscusi (1992) and Smith (1979b), among others, who show zero or small effects of OSHA inspections. Scholz and Gray (1990) report greater effects as, for example, there will be a one percent reduction in injury risks for a ten percent increase in enforcement.

${ }^{59}$ Ruser and Smith (1988) provide a detailed analysis of these records-check inspections and their effect on published injury rates.
} 
Economic analysis of regulations has proven to be important both before and after the regulations are issued. The regulatory impact analyses of prospective regulations provide an evaluation of regulatory costs and benefits that serves as the main basis for regulatory policy debates and internal administrative review. Analyses of the comparative cost-effectiveness of regulatory policies have highlighted possible regulatory imbalances and have indicated how benefits to society could be increased at less cost. Ex post economic analyses of regulatory performance have served a variety of functions, such as highlighting potential inadequacies in enforcement, as well as providing empirical evidence of the extent of behavioral response to regulatory policies.

Often the stated policy concerns are not with respect to an economic efficiency objective but a commitment to improve the environment, make workplaces safe, or promote the safety and efficacy of prescription drugs. Even if the concern is with risk reduction alone, economic analysis provides numerous insights. The performance of the regulatory policy will hinge on the incentives these policies create, both with respect to incentives for regulatory compliance as well as incentives for individuals to undertake risky behaviors that may diminish regulatory effectiveness. Economic studies of risk-risk tradeoffs have also demonstrated that there may be important health-related opportunity costs that may be consequential even if the concern is with risk reduction irrespective of cost. 
Table 1

Age Group Effects on Clear Skies Initiative Benefits

\begin{tabular}{lccc}
\hline & & \multicolumn{2}{c}{$\begin{array}{c}\text { Benefits of Reduced Mortality } \\
\text { (\$ billions undiscounted })\end{array}$} \\
\cline { 3 - 4 } Age Group & $\begin{array}{c}\text { Reduced Annual } \\
\text { Fatalities in 2010 }\end{array}$ & $\begin{array}{c}\text { Constant Value } \\
\text { of Life }\end{array}$ & $\begin{array}{c}\text { Value with } \\
\text { Senior Adjusted }\end{array}$ \\
\hline Base Estimates - Long-Term Exposure: & & 11.6 \\
Adults, 18-64 & 1,900 & 11.6 & 23.1 \\
Adults, 65 and older & 6,000 & 36.6 & \\
Alternative Estimate - Short-Term Exposure: & & 0.2 \\
Children, 0-17 & 30.0 & 0.2 & 6.7 \\
Adults, 18-64 & 1,100 & 6.7 & 14.7 \\
Adults, 65 and older & 3,600 & 21.9 & \\
\hline
\end{tabular}

Note: The reduced annual fatalities figures are from the U.S. EPA (2003), Table 16. The 37 percent senior discount is from the U.S. EPA (2002), p. 35, and the \$6.1 million figure per life is from the U.S. EPA (2003), p. 26. 
Table 2

Opportunity Costs per Statistical Life Saved (OCSLS)

\begin{tabular}{|c|c|c|c|}
\hline Regulation & Year issued & Agency & $\begin{array}{c}\text { OCSLS } \\
\text { (millions of } 2002 \$ \text { ) }\end{array}$ \\
\hline Childproof Lighters & 1993 & CPSC & $\$ 0.1$ \\
\hline Respiratory Protection & 1998 & OSHA-H & 0.1 \\
\hline Logging Operations & 1994 & OSHA-S & 0.1 \\
\hline Electrical Safety & 1990 & OSHA-S & 0.1 \\
\hline Steering Column Protection & 1967 & NHTSA & 0.2 \\
\hline Unvented Space Heaters & 1980 & CPSC & 0.2 \\
\hline Safety Standards for Scaffolds & 1996 & OSHA-S & 0.2 \\
\hline Cabin Fire Protection & 1985 & FAA & 0.3 \\
\hline Trihalomethanes & 1979 & EPA & 0.3 \\
\hline Organ Procurement Regulations & 1998 & HHS & 0.3 \\
\hline AED on Large Planes & 2001 & FAA & 0.3 \\
\hline Mammography Sts & 1997 & HHS & 0.4 \\
\hline Food Labeling Regulations & 1993 & FDA & 0.4 \\
\hline Stability \& Control During Breaking/Trucks & 1995 & NHTSA & 0.4 \\
\hline Electrical Power Generation & 1994 & OSHA-S & 0.4 \\
\hline Passive Restraints/Belts & 1984 & NHTSA & 0.5 \\
\hline Fuel System Integrity & 1975 & NHTSA & 0.5 \\
\hline Underground Construction & 1983 & OSHA-S & 0.5 \\
\hline Head Impact Protection & 1995 & NHTSA & 0.7 \\
\hline Alcohol \& Drug Control & 1985 & FRA & 0.9 \\
\hline Servicing Wheel Rims & 1984 & OSHA-S & 0.9 \\
\hline Reflective Devices for Heavy Trucks & 1999 & NHTSA & 0.9 \\
\hline
\end{tabular}


OCSLS

\begin{tabular}{|c|c|c|c|}
\hline Regulation & Year issued & Agency & (millions of $2002 \$$ ) \\
\hline Seat Cushion Flammability & 1984 & FAA & 1.0 \\
\hline Side Impact \& Autos & 1990 & NHTSA & 1.1 \\
\hline Medical Devices & 1996 & FDA & 1.1 \\
\hline Floor Emergency Lighting & 1984 & FAA & 1.2 \\
\hline Crane Suspended Personnel Platform & 1984 & OSHA-S & 1.5 \\
\hline Low-Altitude Windshear & 1988 & FAA & 1.8 \\
\hline Electrical Equipment Sts./Metal Mines & 1970 & MSHA & 1.9 \\
\hline Trenching and Excavation & 1989 & OSHA-S & 2.1 \\
\hline Traffic Alert \& Collision Avoidance & 1988 & FAA & 2.1 \\
\hline Children's Sleepwear Flammability & 1973 & CPSC & 2.2 \\
\hline Side Doors & 1970 & NHTSA & 2.2 \\
\hline Concrete \& Masonry Construction & 1985 & OSHA-S & 2.4 \\
\hline Confined Spaces & 1993 & OSHA-S & 2.5 \\
\hline Hazard Communication & 1983 & OSHA-S & 3.1 \\
\hline Child Restraints & 1999 & NHTSA & 3.3 \\
\hline Benzene/Fugitive Emissions & 1984 & EPA & 3.7 \\
\hline Rear/Up/Shoulder Belts/Autos & 1989 & NHTSA & 4.4 \\
\hline Asbestos & 1972 & OSHA-H & 5.5 \\
\hline EDB Drinking Water Sts. & 1991 & EPA & 6.0 \\
\hline $\mathrm{NO}_{\mathrm{x}}$ SIP Call & 1998 & $\mathrm{EPA}$ & 6.0 \\
\hline Benzene/Revised: Coke By Products & 1988 & EPA & 6.4 \\
\hline Radionuclides/Uranium Mines & 1984 & EPA & 6.9 \\
\hline Roadway Worker Protection & 1997 & FRA & 7.1 \\
\hline Grain Dust & 1988 & OSHA-S & 11 \\
\hline
\end{tabular}




\begin{tabular}{|c|c|c|c|}
\hline Regulation & Year issued & Agency & $\begin{array}{c}\text { OCSLS } \\
\text { (millions of } 2002 \$ \text { ) }\end{array}$ \\
\hline Electrical Equipment Sts./Coal Mines & 1970 & MSHA & 13 \\
\hline Methylene Chloride & 1997 & OSHA-H & 13 \\
\hline Arsenic/Glass Paint & 1986 & EPA & 19 \\
\hline Benzene & 1987 & OSHA-H & 22 \\
\hline Arsenic/Copper Smelter & 1986 & EPA & 27 \\
\hline Uranium Mill Tailings/Inactive & 1983 & EPA & 28 \\
\hline Hazardous Wastes Listing for Petroleum Sludge & 1990 & EPA & 29 \\
\hline Acrylonitrile & 1978 & OSHA-H & 31 \\
\hline Benzene/Revised: Transfer Operations & 1990 & EPA & 35 \\
\hline 4.4 methylenedianiline & 1992 & OSHA-H & 36 \\
\hline Coke Ovens & 1976 & OSHA-H & 51 \\
\hline $\begin{array}{l}\text { Nat. Primary and Secondary Drinking Water } \\
\text { Regulations Phase II }\end{array}$ & 1991 & EPA & 50 \\
\hline Uranium Mill Tailings/Active & 1983 & EPA & 53 \\
\hline Asbestos & 1986 & OSHA-H & 66 \\
\hline Asbestos/Construction & 1994 & OSHA & 71 \\
\hline Arsenic & 1978 & OSHA-H & 77 \\
\hline Asbestos Ban* & 1989 & EPA & 78 \\
\hline Ethylene Oxide & 1984 & OSHA-H & 80 \\
\hline Lockout/Tagout & 1989 & OSHA-S & 98 \\
\hline Hazardous Waste Management/Wood Products & 1990 & EPA & 140 \\
\hline DES (Cattlefeed) & 1979 & FDA & 170 \\
\hline Benzene/Revised: Waste Operations & 1990 & EPA & 180 \\
\hline Sewage Sludge Disposal & 1993 & EPA & 530 \\
\hline Land Disposal Restrictions & 1990 & EPA & 530 \\
\hline
\end{tabular}




\begin{tabular}{|c|c|c|c|}
\hline Regulation & Year issued & Agency & $\begin{array}{c}\text { OCSLS } \\
\text { (millions of } 2002 \$ \text { ) }\end{array}$ \\
\hline Hazardous Waste: Solids Dioxin & 1986 & EPA & 560 \\
\hline Prohibit Land Disposal & 1988 & EPA & 1,100 \\
\hline Land Disposal Restrictions/Phase II & 1994 & EPA & 2,600 \\
\hline Drinking Water: Phase II & 1992 & EPA & 19,000 \\
\hline Formaldehyde & 1987 & OSHA-H & 78,000 \\
\hline Solid Waste Disposal Facility Criteria & 1991 & EPA & 100,000 \\
\hline
\end{tabular}

Source: Morrall (2003). 


\section{Works Cited}

Adler, R., and D. Pittle (1984). “Cajolery and Command: Are Education Campaigns an

Adequate Substitute for Regulation?," Yale Journal of Regulation 2: 159-194.

Aldy, J. and W.K. Viscusi (2004). “Age Variations in Workers' Value of Statistical Life," NBER Working Paper, No. w10199. Internet: http://www.nber.org/papers/w10199.

American Law Institute (1991). Enterprise Responsibility for Personal Injury-Reporters'Study (American Lung Institute, Philadelphia).

Ames, B.N., and L.S. Gold (1990). “Chemical Carcinogenesis: Too Many Rodent Carcinogens," Proceedings of the National Academy of Sciences, USA 87: 7772-7776.

Ames, B.N., M. Profet, and L.S. Gold (1990). "Nature's Chemicals and Synthetic Chemicals: Comparative Toxicology," Proceedings of the National Academy of Sciences, USA 87: 7777-7781.

Arnould, R.J., and H. Grabowski (1981). “Auto Safety Regulation: An Analysis of Market Failure," Bell Journal of Economics 12(1): 27-48.

Atkinson, S.E., and R. Halvorsen (1990). "The Valuation of Risks to Life: Evidence from the Market for Automobiles," Review of Economics and Statistics 72(1): 133-136.

Becker, G.S. (1968). “Crime and Punishment: An Economic Approach,” Journal of Political Economy 76(2): 169-217.

Becker, G.S., M. Grossman, and K.M. Murphy (1996). “An Empirical Analysis of Cigarette Addiction," American Economic Review 84: 396-418.

Becker, G.S., and K.M. Murphy (1988). “A Theory of Rational Addiction,” Journal of Political Economy 96: 675-700. 
Bernheim, B.D., and A. Rangel (2004). "Addiction and Cue-Triggered Decision Processes," American Economic Review 94(5): 1558-1590.

Bettman, J.R., J.W. Payne, and R. Staelin (1987). “Cognitive Considerations in Presenting Risk Information," in W.K. Viscusi and W.A. Magat, Learning about Risk: Consumer and Worker Responses to Hazard Information (Harvard University Press, Cambridge, MA).

Blomquist, G.C. (1979). "Value of Life Saving: Implications of Consumption Activity,” Journal of Political Economy 87(3): 540-558.

Blomquist, G.C. (1988). The Regulation of Motor Vehicle and Traffic Safety (Kluwer Academic Publishers, Boston).

Blomquist, G.C. (1991). "Motorist Use of Safety Equipment: Expected Benefits or Risk Incompetence," Journal of Risk and Uncertainty 4(2): 135-152.

Breyer, S. (1993). Breaking the Vicious Circle: Toward Effective Risk Regulation (Harvard University Press, Cambridge, MA).

Brookshire, D.S., M.A. Thayer, J. Tschirhart, and W.D. Schulze (1985). "A Test of the Expected Utility Model: Evidence from Earthquake Risks,” Journal of Political Economy 93(2): 369-389.

Burmaster, D.E., and R.N. Harris (1993). "The Magnitude of Compounding Conservatism in Superfund Risk Assessments," Risk Analysis 13(2): 131-134.

Camerer, C.F., and H. Kunreuther (1989). "Decision Processes for Low Probability Events: Policy Implications,” Journal of Policy Analysis and Management 8(4): 565-92.

Camerer, C.F., and M. Weber (1992). "Recent Developments in Modeling Preferences: Uncertainty and Ambiguity," Journal of Risk and Uncertainty 5: 325-370. 
Chapman, K.S., and G. Hariharan (1994). "Controlling for Causality in the Link from Income to Mortality," Journal of Risk and Uncertainty 8(1): 85-93.

Chemical Manufacturers Association (1991). "Analysis of the Impact of Exposure Assumptions on Risk Assessment of Chemicals in the Environment," Prepared by Risk Focus, Versar, Inc.

Cohen, A., and L. Einav (2003). “The Effects of Mandatory Seat Belt Laws on Driving Behavior and Traffic Fatalities," The Review of Economics and Statistics, 85(4):828-843.

Cohen, M.A. (1986). “The Costs and Benefits of Oil Spill Prevention and Enforcement," Journal of Environmental Economics and Management 13: 167-188.

Cohen, M.A. (1987). “Optimal Enforcement Strategy to Prevent Oil Spills: An Application of a Principal-Agent Model with Moral Hazard," Journal of Law and Economics 30: 23-51.

Cohen, M.A. (1992). “Environmental Crime and Punishment: Legal/Economic Theory and Empirical Evidence of Enforcement of Federal Environmental Statutes," The Journal of Criminal Law and Criminology 82(4): 1054-1108.

Crandall, R.W., H.K. Gruenspecht, T.E. Keeler, and L.B. Lave (1986). Regulating the Automobile (Brookings Institute, Washington).

Cropper, M.L., W.N. Evans, S.J. Berardi, M.M. Ducla-Soares, and P.R. Portney (1992). “The Determinants of Pesticide Regulation: A Statistical Analysis of EPA Decision Making," Journal of Political Economy 100(1): 175-197.

Cropper, M.L., and P.R. Portney (1990). "Discounting and the Evaluation of Lifesaving Programs," Journal of Risk and Uncertainty 3(4): 369-379.

Cullen, A.C. (1994). "Measures of Compounding Conservatism in Probabilistic Risk Assessment," Risk Analysis 14 (4): 389-393. 
Desvousges, W., et al. (1993). "Measuring Natural Resource Damages with Contingent Valuation: Tests of Validity and Reliability," in J. Hausman, ed., Contingent Valuation: A Critical Assessment (North Holland Press, Amsterdam), 91-164.

Diamond, P.A., and J.A. Hausman (1994). "Contingent Valuation: Is Some Number Better than No Number?," Journal of Economic Perspectives, 8(4): 45-64.

Ellsberg, D. (1961). "Risk, Ambiguity, and the Savage Axioms," Quarterly Journal of Economics 75: 643-669.

European Commission (1996). Technical Guidance Document in Support of Commission Directive 93/67/EEC on Risk Assessment for New Notified Substances and Commission Regulation No. 1488/94 on risk Assessment for Existing Substances (Office for Official Publications of the European Communities, Luxembourg).

Finkel, A.M. (1989). “Is Risk Assessment Really Too Conservative?” Columbia Journal of Environmental Law 14: 427-467.

Finley, B., and D. Paustenbach (1994). "The Benefits of Probabilistic Exposure Assessment: Three Case Studies Involving Contaminated Air, Water, and Soil,” Risk Analysis 14(1): 53-73.

Fischhoff, B., et al (1981). Acceptable Risk (Cambridge University Press, Cambridge, U.K.). Freeman, A.M. III (1993). The Measurement of Environmental and Resource Values (Resources for the Future, Washington).

Freeman, A.M. III (2002). "Environmental Policy Since Earth Day I: What Have We Gained?" The Journal of Economic Perspectives 16(1): 125-146).

Gayer, T. (2004). “The Fatality Risks of Sport-Utility Vehicles, Vans, and Pickups Relative to Cars," Journal of Risk and Uncertainty 28(2): 103-133. 
Gerdtham, U.-G., and M. Johanneson (2002). "Do Life-Saving Regulations Save Lives?," Journal of Risk and Uncertainty 24(3): 231-249.

Gollier, C., and N. Treich (2003). "Decision-Making Under Scientific Uncertainty: The Economics of the Precautionary Principle," Journal of Risk and Uncertainty 27(1): 77103.

Graham, J., B. Hung-Chang, and J.S. Evans (1992). "Poorer is Riskier," Risk Analysis 12(3): 333-337.

Gruber, J., and B. Koszegi (2001). “Is Addiction 'Rational'? Theory and Evidence,” Quarterly Journal of Economics, 116(4): 1261-1303.

Hahn, R.W., R.W. Lutter, and W.K. Viscusi (2000). Do Federal Regulations Reduce Mortality? (AEI-Brookings Joint Center for Regulatory Studies, Washington).

Hanemann, W.M. (1994). "Valuing the Environment Through Contingent Valuation," Journal of Economic Perspectives 8(4): 19-43.

Hamilton, J.T. (1995). “Testing for Environmental Racism: Prejudice, Profits, Political Power?,” Journal of Policy Analysis and Management 14(1): 107-32.

Hamilton, J.T., and W.K. Viscusi (1999). Calculating Risks?: The Spatial and Political Dimensions of Hazardous Waste Policy (MIT Press, Cambridge, MA).

Harrington, W., and P.R. Portney (1987). "Valuing the Benefits of Health and Safety Regulations," Journal of Urban Economics 22(1): 101-112.

Hersch, J. (1998). "Compensating Differentials for Gender-Specific Job Injury Risks," American Economic Review 88(3): 598-607. 
Hersch, J. (2002). “Breast Implants: Regulation, Litigation, and Science,” in W. K. Viscusi, ed., Regulation through Litigation (AEI-Brookings Joint Center for Regulatory Studies, Washington), 142-177.

Hersch, J., and T.S. Pickton (1995). "Risk-Taking Activities and Heterogeneity of Job-Risk Tradeoffs, “ Journal of Risk and Uncertainty 11: 205-217.

Hersch, J., and W.K. Viscusi (1990). “Cigarette Smoking, Seatbelt Use, and Differences in Wage-Risk Tradeoffs," Journal of Human Resources 25(2): 202-227.

Horowitz, J.K., and R.T. Carson (1990). “Discounting Statistical Lives,” Journal of Risk and Uncertainty 3(4): 403-413.

Huber, P. (1988). Liability: The Legal Revolution and its Consequences (Basic Books, New York).

Ippolito, P.M., and R.A. Ippolito (1984). "Measuring the Value of Life Saving from Consumer Reactions to New Information," Journal of Public Economics 25: 53-81.

Jenni, K.E., and G. Loewenstein (1997). “Explaining the 'Identifiable Victim Effect,'” Journal of Risk and Uncertainty 14(3):235-257.

Johannesson, M., P.-O. Johansson, and R.M. O’Conor (1996). “The Value of Private Safety Versus the Value of Public Safety," Journal of Risk and Uncertainty 13(3):263-275.

Johansson, P.-O. (2002). "The Definition and Age-Dependency of the Value of a Statistical Life," Journal of Risk and Uncertainty 25(3): 251-263.

Jones-Lee, M.W. (1976). The Value of Life: An Economic Analysis (University of Chicago Press, Chicago).

Jones-Lee, M.W. (1989). The Economics of Safety and Physical Risk (Basil Blackwell, Oxford). 
Jones-Lee, M.W. (1991). “Altruism and the Value of Other People's Safety," Journal of Risk and Uncertainty 4(2): 213-219.

Jones-Lee, M.W., M. Hammerton, and P.R. Philips (1985). "The Value of Safety: Results of a National Sample Survey," Economic Journal 95: 49-72.

Kahneman, D., and J.L. Knetsch (1992). "Valuing Public Goods: The Purchase of Moral Satisfaction," Journal of Environmental Economics and Management 22: 57-70.

Keeler, T.E. (1994). "Highway Safety, Economic Behavior, and Driving Environment," American Economic Review 84(3): 684-693.

Keeney, R.L. (1990). “Mortality Risks Induced by Economic Expenditures,” Risk Analysis 10(1): 147-159.

Kniesner, T.J., and J.D. Leeth (1991). “Compensating Wage Differentials for Fatal Injury Risk in Australia, Japan, and the United States," Journal of Risk and Uncertainty 4(1): 75-90.

Kniesner, T.J., W.K. Viscusi, and J.P. Ziliak (2004). "Life-Cycle Consumption and the AgeAdjusted Value of Life," Harvard University John M. Olin Center for Law, Economics, and Business Working Paper 459.

Krupnick, A., A. Alberini, M. Cropper, N. Simon, B. O'Brien, R. Goeree, and M. Heintzelman (2002). “Age, Health, and the Willingness to Pay for Mortality Risk Reductions: The Contingent Valuation Survey of Ontario Residents," Journal of Risk and Uncertainty 24(2): 161-186.

Kunreuther, H., et al. (1978). Disaster Insurance Protection: Public Policy Lessons (Wiley, New York).

Kunreuther, H., R. Hogarth, and J. Meszaros (1993). "Insurer Ambiguity and Market Failure," Journal of Risk and Uncertainty 7(1): 71-87. 
Levitt, S.D., and J. Porter (201). "Sample Selection in the Estimation of Air Bag and Seat Belt Effectiveness," Review of Economics and Statistics 83(4): 603-615.

Lichtenstein, S., P. Slovic, B. Fischhoff, U. Layman, and B. Combs (1978). “Judged Frequency of Lethal Events," Journal of Experimental Psychology: Human Learning and Memory 4: $551-578$.

Liu, J.-T., and C.-R. Hsieh (1995). "Risk Perception and Smoking Behavior: Empirical Evidence from Taiwan," Journal of Risk and Uncertainty 11(2): 139-57.

Lofstedt, R. (2004). “The Swing of the Regulatory Pendulum in Europe: From Precautionary Principle to (Regulatory) Impact Analysis." Journal of Risk and Uncertainty 28(3): 237260.

Lutter, R., and E. Mader (2002). "Litigating Lead-Based Paint Hazards," in W. K. Viscusi, ed., Regulation through Litigation (AEI-Brookings Joint Center for Regulatory Studies, Washington), 106-135.

Lutter, R., and J.F. Morrall III (1994). "Health-Health Analysis: A New Way to Evaluate Health and Safety Regulation," Journal of Risk and Uncertainty 8(1): 43-46.

Lutter, R., J.F. Morrall III, and W.K. Viscusi (1999). “The Cost-per-Life-Saved Cutoff for Safety-Enhancing Regulations,” Economic Inquiry 37(4): 599-608.

Magat, W.A., and W.K. Viscusi (1992). Informational Approaches to Regulation (MIT Press, Cambridge, MA).

Magat, W.A., W.K. Viscusi, and J. Huber (August 1996). “A Reference Lottery Metric for Valuing Health," Management Science 42(8): 1118-1129.

Manning, R.L. (1994). "Changing Rules in Tort Law and the Market for Childhood Vaccines," Journal of Law and Economics 37(1): 247-275. 
Manning, W.G., E.B. Keeler, J.P. Newhouse, E.M. Sloss, and J. Wasserman (1989). “Taxes of Sin: Do Smokers and Drinkers Pay Their Way?" Journal of the American Medical Association 26(11): 1604-9.

McClelland, G.H., W.D. Schulze, and B. Hurd (1990). "The Effects of Risk Beliefs on Property Values: A Case Study of a Hazardous Waste Site," Risk Analysis 10(4): 485-497.

Michigan Manufacturers Association (1993). “A Comparison of Monte Carlo Simulation-Based Exposure Estimates with Estimates Calculated Using EPA and Suggested Michigan Manufacturers Association Exposure Factors," Prepared by ENVIRON Corporation.

Mishan, E.J. (1971). "Evaluation of Life and Limb: A Theoretical Approach,” Journal of Political Economy, 79(4): 687-705.

Moore, M.J., and W.K. Viscusi (1990). Compensating Mechanisms for Job Risks: Wages, Workers' Compensation, and Product Liability (Princeton University Press, Princeton).

Morrall III, J.F. (1986). “A Review of the Record,” Regulation 10(2): 25-34.

Morrall III, J.F. (2003). "Saving Lives: A Review of the Record,” Journal of Risk and Uncertainty 27(3): 221-237.

Murray, C.J.L., and A.D. Lopez (1996). The Global Burden of Disease: Summary (World Health Organization, Geneva).

Nader, R. (1965). Unsafe at Any Speed (Grossman Publishers, New York).

National Academy of Sciences (1990). Developing New Contraceptives: Obstacles and Opportunities (National Academy Press, Washington).

National Research Council (1983). Risk Assessment in the Federal Government: Managing the Process (National Academy Press, Washington). 
National Research Council (1994). Science and Judgment in Risk Assessment (National Academy Press, Washington).

National Research Council (1996). Carcinogens and Anticarcinogens in the Human Diet (National Academy Press, Washington).

National Safety Council (2004). Injury Facts (National Safety Council, Itasca, IL).

Nichols, A.L., and R.J. Zeckhauser (1986). “The Perils of Prudence: How Conservative Risk Assessments Distort Regulation,” Regulation 10(2): 13-24.

Office of Science and Technology Policy, Executive Office of the President (March 14, 1985). Chemical Carcinogens: A Review of the Science and its Associated Principles (Federal Register 50: 10371-10442).

Peltzman, S. (1975). “The Effects of Automobile Safety Regulation,” Journal of Political Economy 83(4): 677-725.

Polinsky, A.M., and S. Shavell (1979). "The Optimal Tradeoff between the Probability and Magnitude of Fines," American Economic Review 69(5): 880-891.

Polinsky, A.M., and S. Shavell (1992). "Enforcement Costs and the Optimal Magnitude and Probability of Fines," Journal of Law and Economics 35(1): 133-148.

Polinsky, A.M., and S. Shavell (1994). "Should Liability Be Based on the Harm to the Victim or the Gain to the Injurer?" Journal of Law, Economics, and Organization 10(2): 427-437.

Portney, P.R. (1981). "Housing Prices, Health Effects, and Valuing Reductions in Risk of Death," Journal of Environmental Economics and Management 8: $72-78$.

Portney, P.R. (1994). “The Contingent Valuation Debate: Why Economists Should Care," Journal of Economic Perspectives 8(4): 3-17. 
Posner, R.A. (2004). Catastrophe: Risk and Response (Oxford University Press, New York).

Raiffa, H. (1961). "Risk, Ambiguity, and the Savage Axioms: Comment," Quarterly Journal of Economics 75: 690-94.

Revesz, R.L. (1999). “Environmental Regulation, Cost-Benefit Analysis, and the Discounting of Human Lives," Columbia Law Review 99: 941-1017.

Rosen, S. (1988). "The Value of Changes in Life Expectancy," Journal of Risk and Uncertainty 1(3): 285-304.

Ruser, J.W., and R.S. Smith (1988). “The Effect of OSHA Records-Check Inspections on Reported Occupational Injuries in Manufacturing Establishments,” Journal of Risk and Uncertainty 1(4): 415-435.

Samuelson, W., and R. Zeckhauser (1988). “Status Quo Bias in Decision Making,” Journal of Risk and Uncertainty 1(1): 7-59.

Schelling, T.C. (1968). "The Life You Save May Be Your Own,” in S.B. Chase, Jr., ed., Problems in Public Expenditure Analysis (Brookings Institute, Washington), 127-162.

Schelling, T.C. (1978). Micromotives and Macrobehavior (W.W. Norton, New York).

Schelling, T.C. (1984). Choice and Consequence (Harvard University Press, Cambridge, MA).

Scholz, J.T., and W.B. Gray (1990). “OSHA Enforcement and Workplace Injuries: A Behavioral Approach to Risk Assessment," Journal of Risk and Uncertainty 3(3): 283305.

Shavell, S. (1987). Economic Analysis of Accident Law (Harvard University Press, Cambridge, MA).

Shavell, S. (2004). Foundations of Economic Analysis of Law (Harvard University Press, Cambridge, MA). 
Shepard, D.S., and R.J. Zeckhauser (1984). “Survival Versus Consumption,” Management Science 30(4): 423-439.

Smith, R.S. (1979a). “Compensating Wage Differentials and Public Policy: A Review," Industrial and Labor Relations Review 32(3): 339-352.

Smith, R.S. (1979b). “The Impact of OSHA Inspections on Manufacturing Injury Rates," Journal of Human Resources 14: 145-170.

Smith, V.K., and W.H. Desvousges (1986). "The Value of Avoiding a LULU: Hazardous Waste Disposal Sites," Review of Economics and Statistics 68: 293-299.

Sunstein, C. (2002). Risk and Reason: Safety, Law, and the Environment (Cambridge University Press, Cambridge, U.K.; New York).

Tengs, T.O., M.E. Adams, J.S. Pliskin, D.G. Safran, J.E. Siegel, M.C. Weinsten, and J.D. Graham (1995). "Five-Hundred Life-Saving Interventions and their Cost-Effectiveness," Risk Analysis 15(3): 369-390.

Thaler, R., and S. Rosen (1976). “The Value of Saving a Life: Evidence from the Labor Market," in N. Terleckyj, ed., Household Production and Consumption (National Bureau of Economic Research, New York), 265-298.

U.S. Environmental Protection Agency (1987). The Risk Assessment Guidelines of 1986. EPA600/8-87/045. (Guidelines for Carcinogen Risk Assessment; Guidelines for Mutagenicity Risk Assessment; Guidelines for the Health Risk Assessment of Chemical Mixtures; Guidelines for the Health Assessment of Suspect Developmental Toxicants; Guidelines for Estimating Exposures) (U.S. EPA, Office of Health and Environmental Assessment, Washington). 
U.S. Environmental Protection Agency (December 2, 1988). Proposed Guidelines for ExposureRelated Measurements (Federal Register 53: 48830-48853).

U.S. Environmental Protection Agency (May 29, 1992). Guidelines for Exposure Assessment (Federal Register 57: 22888-22938).

U.S. Environmental Protection Agency (April 23, 1996). Proposed Guidelines for Carcinogen Risk Assessment (Federal Register 61: 17960-18011).

U.S. Environmental Protection Agency. (2002). Technical Addendum: Methodologies for the Benefit Analysis of the Clear Skies Initiative (USEPA, Washington).

U.S. Environmental Protection Agency. (2003). Technical Addendum: Methodologies for the Benefit Analysis of the Clear Skies Act of 2003 (USEPA, Washington).

U.S. General Accounting Office (July 1992). Risk-Risk Analysis: OMB's Review of a Proposed OSHA Rule (Report to the Chairman, Committee on Governmental Affairs, U.S. Senate).

Viscusi, W.K. (1984). "The Lulling Effect: The Impact of Child-Resistant Packaging on Aspirin and Analgesic Ingestions," American Economic Review 74(2): 324-327.

Viscusi, W.K. (1992). Fatal Tradeoffs: Public and Private Responsibilities for Risk (Oxford University Press, Oxford).

Viscusi, W.K. (1994). "Mortality Effects of Regulatory Costs and Policy Evaluation Criteria," Rand Journal of Economics 25(1): 94-109.

Viscusi, W.K. (1997). “Alarmist Decisions with Divergent Risk Information,” The Economic Journal 107: 1657-1670.

Viscusi, W.K. (1998). Rational Risk Policy (Oxford University Press, Oxford).

Viscusi, W.K. (2002). Smoke-Filled Rooms: A Postmortem on the Tobacco Deal (Chicago University Press, Chicago). 
Viscusi, W.K., and J.E. Aldy (2003). "The Value of a Statistical Life: A Critical Review of Market Estimates Throughout the World," Journal of Risk and Uncertainty 27(1): 5-76.

Viscusi, W.K., J.T. Hamilton, and P.C. Dockins (1997). “Conservative versus Mean Risk Assessments: Implications for Superfund Policies," Journal of Environmental Economics and Management 34: 187-206.

Viscusi, W.K., and J. Hersch (2001). “Cigarette Smokers as Job Risk Takers,” Review of Economics and Statistics 83(2): 269-280.

Viscusi, W.K., and W.A. Magat (1987). Learning about Risk: Consumer and Worker Responses to Hazard Information (Harvard University Press, Cambridge, MA).

Viscusi, W.K., W.A. Magat, and J. Huber (1987). “An Investigation of the Rationality of Consumer Valuations of Multiple Risks," Rand Journal of Economics 18(4): 465-479.

Viscusi, W.K., and M.J. Moore (1993). "Product Liability, Research and Development, and Innovation," Journal of Political Economy 101: 161-184.

Viscusi, W.K., and R. Zeckhauser (2004). “The Denominator Blindness Effect: Accident Frequencies and the Misjudgment of Recklessness," American Law and Economics Review 6(1): 72-94.

Zeckhauser, R. (1975). “Procedures for Valuing Lives,” Public Policy 23(4): 419-464. 